\title{
Measured Performance of a Varied Airflow Small-Diameter Duct System
}

Andrew Poerschke IBACOS, Inc. 


\section{NOTICE}

This report was prepared as an account of work sponsored by an agency of the United States government. Neither the United States government nor any agency thereof, nor any of their employees, subcontractors, or affiliated partners makes any warranty, express or implied, or assumes any legal liability or responsibility for the accuracy, completeness, or usefulness of any information, apparatus, product, or process disclosed, or represents that its use would not infringe privately owned rights. Reference herein to any specific commercial product, process, or service by trade name, trademark, manufacturer, or otherwise does not necessarily constitute or imply its endorsement, recommendation, or favoring by the United States government or any agency thereof. The views and opinions of authors expressed herein do not necessarily state or reflect those of the United States government or any agency thereof.

This report is available at no cost from the National Renewable Energy Laboratory (NREL) at www.nrel.gov/publications.

Available electronically at SciTech Connect http:/www.osti.gov/scitech

Available for a processing fee to U.S. Department of Energy and its contractors, in paper, from:

U.S. Department of Energy

Office of Scientific and Technical Information

P.O. Box 62

Oak Ridge, TN 37831-0062

OSTI http://www.osti.gov

Phone: 865.576.8401

Fax: 865.576.5728

Email: reports@osti.gov

Available for sale to the public, in paper, from:

U.S. Department of Commerce

National Technical Information Service

5301 Shawnee Road

Alexandria, VA 22312

NTIS http://www.ntis.gov

Phone: 800.553 .6847 or 703.605 .6000

Fax: 703.605.6900

Email: orders@ntis.gov 


\title{
Measured Performance of a Varied Airflow Small-Diameter Duct System
}

\author{
Prepared for: \\ The National Renewable Energy Laboratory \\ On behalf of the U.S. Department of Energy's Building America Program \\ Office of Energy Efficiency and Renewable Energy \\ 15013 Denver West Parkway \\ Golden, CO 80401 \\ NREL Contract No. DE-AC36-08GO28308 \\ Prepared by: \\ Andrew Poerschke \\ IBACOS, Inc. \\ 2214 Liberty Avenue \\ Pittsburgh, PA 15222 \\ NREL Technical Monitor: Stacey Rothgeb \\ Prepared under Subcontract No. KNDJ-0-40341-04
}

March 2017 
The work presented in this report does not represent performance of any product relative to regulated minimum efficiency requirements.

The laboratory and/or field sites used for this work are not certified rating test facilities. The conditions and methods under which products were characterized for this work differ from standard rating conditions, as described.

Because the methods and conditions differ, the reported results are not comparable to rated product performance and should only be used to estimate performance under the measured conditions. 


\section{Contents}

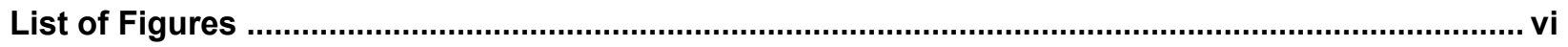

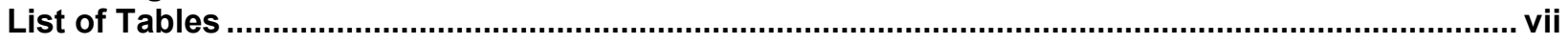

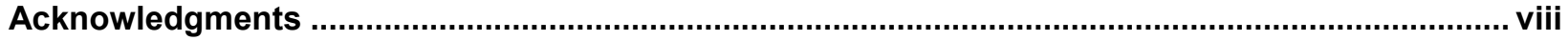

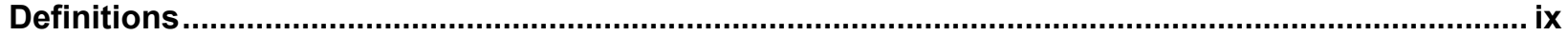

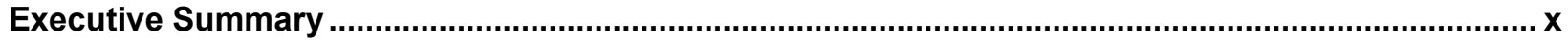

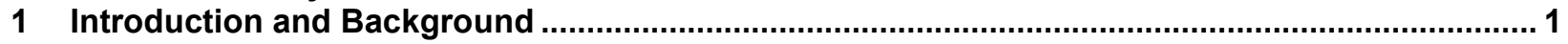

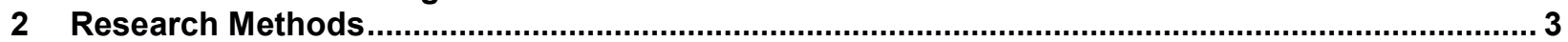

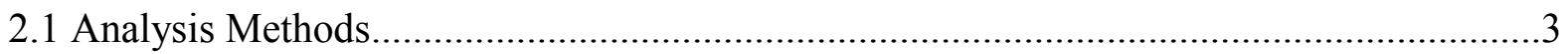

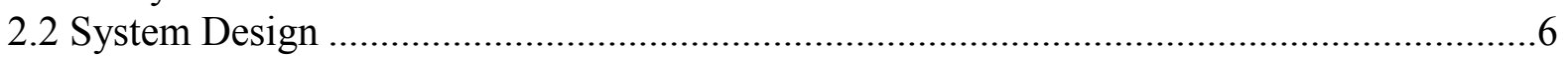

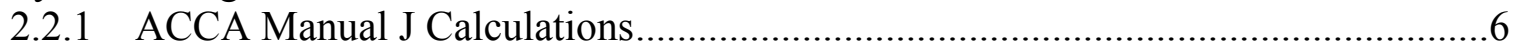

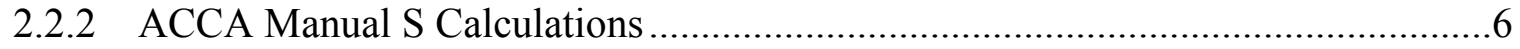

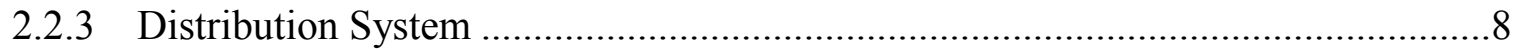

2.3 Field Measurements and Short-Term Testing.............................................................. 10

2.4 Assessment of House Performance With Respect to Comfort Criteria ........................... 11

2.5 Assessment of Fan Efficacy.................................................................................... 12

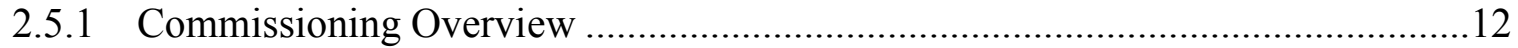

2.5.2 Measured Airflow at Each Supply Register........................................................ 12

2.5.3 Whole-System Airflow Measured at the Return Plenum ......................................14

2.5.4 Measured Supply Air Velocity and Temperature at Three Fan Speeds.................14

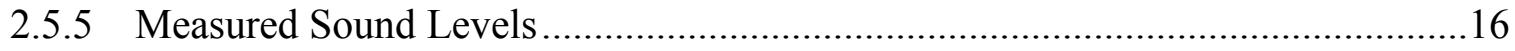

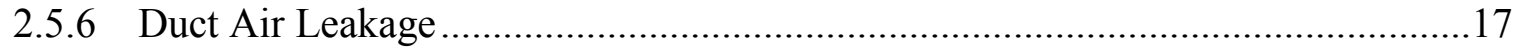

2.5.7 Whole-House Air Infiltration....................................................................... 17

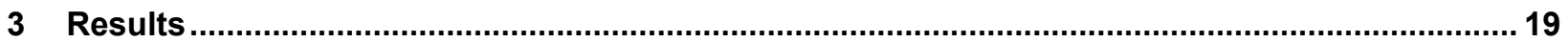

3.1 ASHRAE Standard 55-2010 Temperature Variations With Time .................................19

3.2 ACCA Manual RS Room-to-Thermostat Temperature Uniformity ...............................20

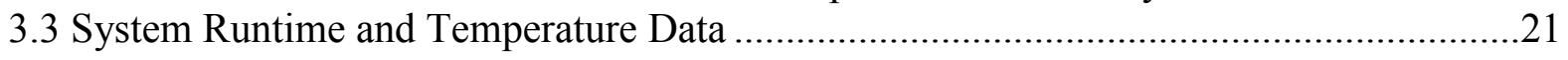

3.4 Fan Energy Relation to Delivered Energy ...........................................................24

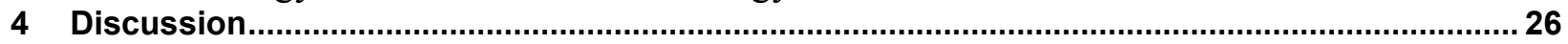

4.1 ASHRAE Standard 55-2010 Temperature Variations With Time .................................26

4.2 ACCA Manual RS Room-to-Thermostat Temperature Uniformity ...............................26

4.3 Fan Energy Relation to Delivered Energy ...............................................................27

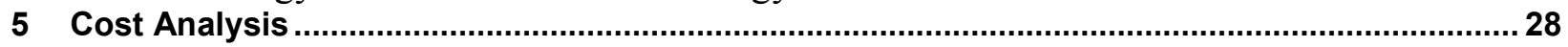

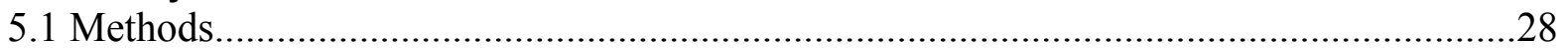

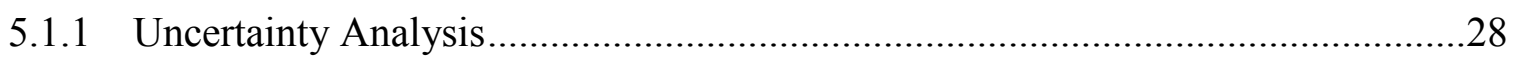

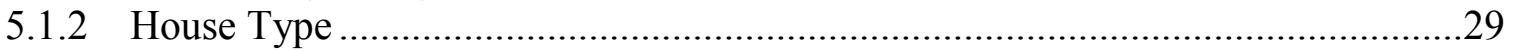

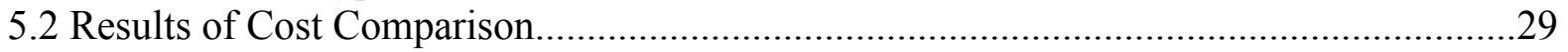

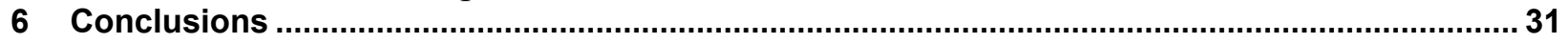

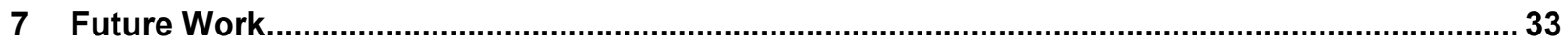

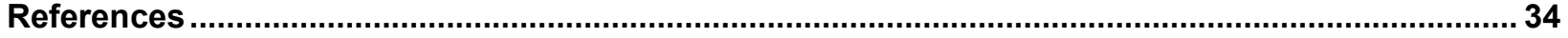

Appendix: Instrument and Test HVAC System Commissioning .................................................... 36

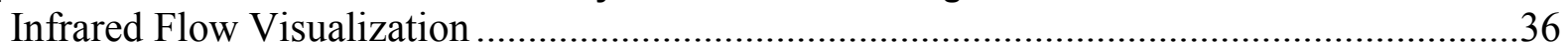

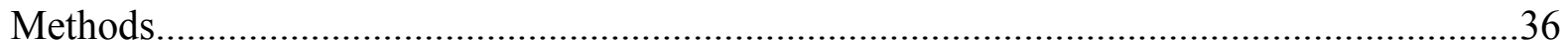

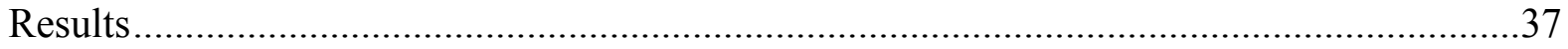

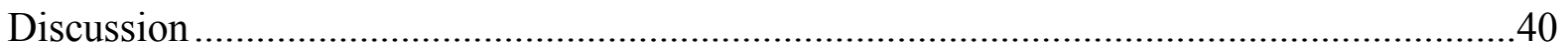




\section{List of Figures}

Figure 1. Front view of the Pittsburgh unoccupied test house ..................................................... 4

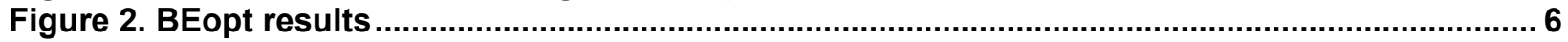

Figure 3. Photograph from the interior of bedroom 3 showing the supply outlet and air

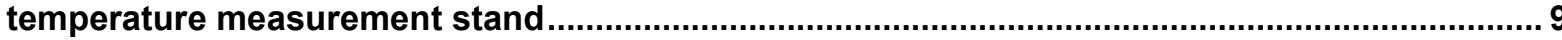

Figure 4. Ductwork layout: first floor (left) and second floor (right); (the partially open door position shown here does not represent the door position used in the house during testing) .. 9

Figure 5. Measuring airflow rate using a hot wire anemometer...................................................... 15

Figure 6. Typical blower door testing (not the actual test house) …................................................ 18

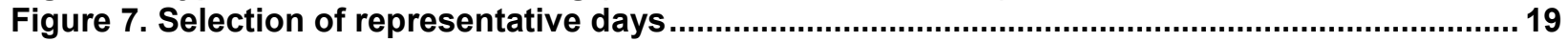

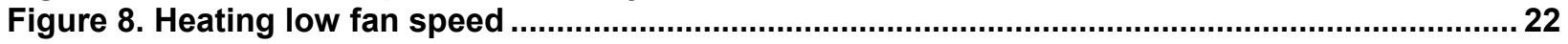

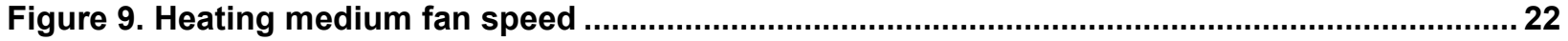

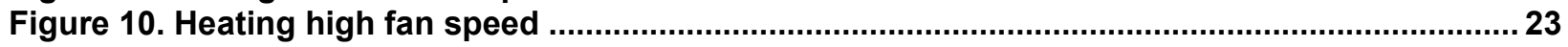

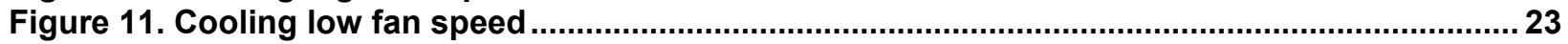

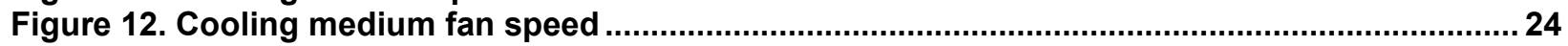

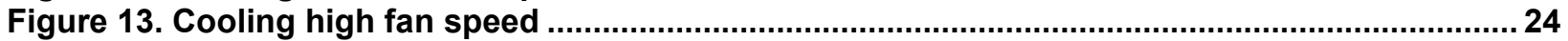

Figure 14. Bulkhead (dropped ceiling) location and duct layout for small-diameter ducts .............. 29

Figure 15. Wide-angle IR camera (left) facing black felt IR viewing screen positioned adjacent to a wall and parallel to the primary register airflow path ............................................................... 36

Figure 16. IR photo of the black felt screen during low-speed cooling system operation

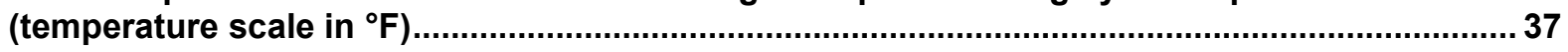

Figure 17. IR photo of the black felt screen during medium-speed cooling system operation

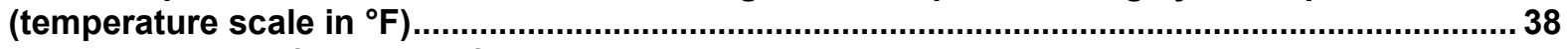

Figure 18. IR photo of the black felt screen during high-speed cooling system operation

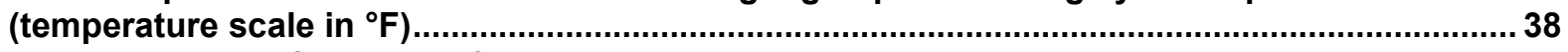

Figure 19. IR photo of the black felt screen during low-speed heating system operation (temperature scale in ${ }^{\circ} \mathrm{F}$ )

Figure 20. IR photo of the black felt screen during medium-speed heating system operation (temperature scale in ${ }^{\circ} \mathrm{F}$ )

Figure 21. IR photo of the black felt screen during high-speed heating system operation (temperature scale in ${ }^{\circ} \mathrm{F}$ ).

Unless otherwise noted, all figures and photos were created by IBACOS. 


\section{List of Tables}

Table 1. Pittsburgh Test House Specifications ............................................................................. 5

Table 2. Varied Airflow Small-Duct System Design and Measured Room Airflows at Medium Fan

Speed.

Table 3. Measurement Types and Quantities During Short-Term Testing ........................................ 10

Table 4. Field Measured Supply Airflow Rate at Each Register-Heating Mode............................... 13

Table 5. Field Measured Supply Airflow Rate at Each Register-Cooling Mode ............................. 14

Table 6. VelociCheck and Data-Logger Recorded Supply Air Velocity and Temperature in Cooling Mode at Three Fan Speeds .................................................................................... 16

Table 7. VelociCheck and Data-Logger Recorded Supply Air Velocity and Temperature in

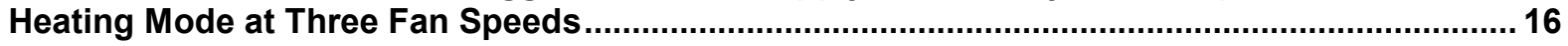

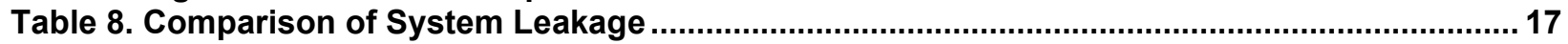

Table 9. Comparison of Whole-House Infiltration........................................................................... 18

Table 10. Summary of Data Analysis Methods .......................................................................... 19

Table 11. Heating Season Test Results Based on ASHRAE Standard 55-2010 Section 5.2.5, ${ }^{*}$

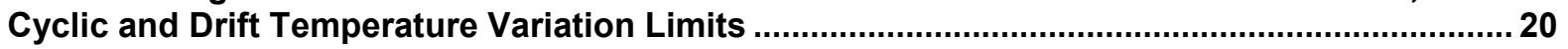

Table 12. ACCA Manual RS Temperature Deviation Failure Rate ....................................................... 21

Table 13. Energy Performance on Representative Days .............................................................. 25

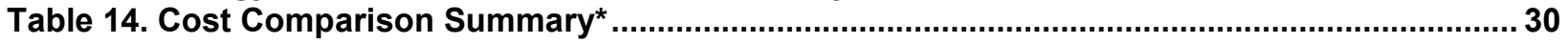

Unless otherwise noted, all tables were created by IBACOS. 


\section{Acknowledgments}

The author acknowledges Unico, Inc. for providing the prototype heating, ventilating, and airconditioning equipment used in this study. The author also is grateful to Armin Rudd of ABT Systems, LLC, for providing technical insight and guidance in drafting the final report. 


\section{Definitions}

ACCA

$\mathrm{ACH}$

AHU

BEopt $^{\mathrm{TM}}$

Btu

$\mathrm{cfm}$

HVAC

IR
Air Conditioning Contractors of America

Air changes per hour

Air handling unit

Building Energy Optimization (software)

British thermal unit

Cubic feet per minute

Heating, ventilating, and air conditioning

Infrared 


\section{Executive Summary}

In this study, researchers with the U.S. Department of Energy's Building America team IBACOS built on research previously done in two new-construction unoccupied test houses-one in Pittsburgh, Pennsylvania (Poerschke and Stecher 2014) and one in Fresno, California (Stecher and Poerschke 2013). Specific traditional central air distribution systems were installed in each of these low-load homes. For this study, the cold-climate new-construction unoccupied test house in Pittsburgh, Pennsylvania, was modified to test the performance of a heating, ventilating, and air-conditioning (HVAC) system with varied airflow and small-diameter ducts.

The main goal of the small-diameter duct system is to simplify the task of bringing ductwork inside conditioned space, particularly on the single-story slab-on-grade type of home that is prevalent in the South and Southeast. Guidance is provided here to homebuilders and HVAC contractors on cost and performance tradeoffs between the conventional duct system and the small-diameter duct system.

Comparisons were made between variable-capacity heat pump operation modes with three constant airflow rates to determine the ideal tradeoff between maximizing thermal comfort and minimizing fan energy consumption.

ASHRAE Standard 55 (ASHRAE 2010a) was used to set limit metrics for temporal temperature variation; Air Conditioning Contractors of America (ACCA) Manual RS (Rutkowski 1997) was used to set a limit on spatial temperature uniformity (room-to-thermostat uniformity). The smalldiameter duct system was able to meet the temporal temperature variation limits much better than the spatial temperature uniformity limits.

All cooling mode tests met the ASHRAE temporal temperature variation limits; however, highspeed fan heating mode tests showed $7 \%-15 \%$ failure rates over 15 -minute to 4 -hour time periods. These were caused by condenser coil defrost cycles during which no auxiliary heat system operated and were most evident with high fan speed because the house cooled faster during the same defrosting time.

In heating mode the basement and the master bedroom had 100\% incidence of ACCA temperature uniformity failure at all fan speeds. During typical heating mode days the master bedroom, which was at the end of the longest duct run, was consistently $3^{\circ}-5^{\circ} \mathrm{F}$ cooler than the thermostat reading. This bedroom was at the end of the longest duct run. Bedroom 3 had a high incidence of temperature nonuniformity at high fan speed; bedroom 4 had a high incidence of temperature nonuniformity at low fan speed because of insufficient (below-design) airflow. In cooling mode, bedroom 3 had a high incidence of temperature nonuniformity at both mediumspeed (design) and low-speed airflow. Bedroom 4 showed high room-to-thermostat nonuniformity at all airflow levels. Both of those bedrooms had below-design cooling airflow but above-design heating airflow. During typical sunny days in cooling mode, the south-facing and west-facing bedrooms overheated by more than $3^{\circ} \mathrm{F}$ for $3 \%-40 \%$ of the time because of solar heat gains. Running the system at a higher fan speed reduced the percentage of overheating time from $40 \%$ to $18 \%$ in one case on similar sunny summer days. 
The small-diameter duct system operated with a total external static pressure that ranged from $0.12-1.22$ in. water column compared to published values of $0.41-0.50$ that can be expected for traditional duct systems. The measured external static pressure of the small-diameter duct system at the medium fan speed (standard design condition) was $0.41 \mathrm{in}$. water column, which was at the low end of traditional duct systems. Measured fan efficacy was $0.15-0.56 \mathrm{~W} / \mathrm{ft}^{3} / \mathrm{min}$ of airflow for the small-diameter duct system. At the medium and high speeds the indoor fan operated almost continuously and the heat pump thermal output modulated; the small-diameter duct system used more fan energy than the traditional duct system. Both medium and high speeds were needed at times to meet the temperature set point and to achieve temperature uniformity. A control strategy that runs the fan at the lowest speed to meet most load hours and switches to higher speeds only under peak load conditions would offer the best tradeoff between comfort and fan energy use.

The research team used black felt infrared imagery of the supply outlet airflow pattern as a qualitative measure of in-room air mixing. Based on these observations, lower airflow rates combined with longer system runtime would provide superior occupant comfort because of less air stratification and lower peak room air velocities.

This work has shown that duct configuration and zone temperature control issues remain. These issues need to be resolved for small-diameter duct systems to reliably provide room-tothermostat temperature uniformity throughout low-load homes.

A cost advantage was estimated for installing the small-diameter duct system inside conditioned space compared to using traditionally sized ducts in the same situation. For the small-diameter duct system, the bulkhead construction cost $\$ 100$ less and the duct material and air handler unit combined cost $\$ 2,100$ less; however, the outdoor heat pump unit cost $\$ 1,700$ more, which yielded a predicted net savings of $\$ 500$. These estimates for small-diameter high-velocity systems compared to traditional systems are for discussion purposes only and have a relatively high uncertainty.

Future work is suggested using data measured in this study and a detailed whole-house TRNSYS computer model to further understand the impact of the small-diameter duct system operating in different climate zones and house types. 


\section{Introduction and Background}

Current engineering guidelines for forced-air space conditioning systems use a methodology developed more than 50 years ago that is based on the concept that buildings are dominated by externally driven shell loads (Straub 1956). Although instantaneous loads are still externally dominated, significant advances in thermal enclosure performance mean that these loads can be strongly influenced by internal gains, hourly loads in different rooms, and thermal lag. All these factors require rethinking the traditional space conditioning system. Individual rooms isolated from the main space thermostat tend to have unique load variations based on solar gains. Traditional, centrally ducted, and controlled systems can be ineffective at addressing these individual room loads because interior partition walls do not allow enough air to move to the thermostat space. Controlling these systems in a quasi-multizone or fully multizone manner can be effective. Quasi-multizone control may employ multiple temperature sensors in individual spaces but control airflow operation to the entire space based on an average or weighted average of those readings. Fully multizone control would employ multiple temperature sensors in individual spaces but control airflow operation to only the individual spaces based on their individual temperature readings. These multizone control methods have associated costs so other solution strategies may be required. One such alternative strategy is the multiflow small-diameter duct system that is connected to variable-capacity heating and cooling equipment, which is studied here.

The difficulty of creating central space conditioning systems (i.e., design, balancing, operation, supply outlet locations, and fan operation strategies) for low-load and very-low-load homes (i.e., loads lower than $10 \mathrm{Btu} / \mathrm{h}-\mathrm{ft}^{2}$ of floor area) has been well documented through modeling and field measurements (IBACOS 2006a, 2006b, and 2007; Rittelmann 2008; Broniek 2008). Aldrich (2009) documented the significant impact that internal gains of occupants and simple electronics can have during much of the year in the heating season in houses with single-point heating systems and minimal distribution systems.

The U.S. Department of Energy's Building America research team IBACOS has studied passive air transfer from the main space of the house to bedrooms with the doors open and the doors closed in two new-construction unoccupied test houses-one in Pittsburgh, Pennsylvania (Poerschke and Stecher 2014), and one in Fresno, California (Stecher and Poerschke 2013). When interior doors are closed, passive air transfer grilles do not provide adequate air transfer to maintain spaces within Air Conditioning Contractors of America (ACCA) Manual RS recommendations (Rutkowski 1997).

Based on research in houses that meet the Building America 50\% energy savings targetsresearch that the IBACOS team performed through 2012 at the unoccupied test houses in Pittsburgh, Pennsylvania, and Fresno, California, along with past research by IBACOS (IBACOS 2006a, 2006b, 2007; Rittelmann 2008; Broniek 2008) and by others (as cited previously) — the research team reached the following conclusions:

- Because external and internal gains occur during peak and nonpeak load conditions, individual rooms with closed doors may not achieve temperature uniformity per the ACCA Manual RS (Rutkowski 1997) or even meet the 2012 International Energy Conservation Code levels of efficiency (IECC 2012) with right-sized central systems that 
use one centrally located thermostat per multiroom zone. Production builder partners have communicated this concern to the research team.

- Whole-house average air temperature stratification is rarely greater than $3^{\circ} \mathrm{F}$ from floor to ceiling when supply air outlets are properly selected and located to engage the whole volume of room air and appropriate return air strategies are implemented (Rittelmann (2008).

- Bringing conventionally sized ductwork into conditioned space is a significant challenge to conventional production homebuilders, particularly in the single-story slab-on-grade type of home that is prevalent in the South and Southeast.

- Based on occupant preferences, interior doors may remain open all day. However, from a production builder's standpoint the worst-case scenario is a house with interior partition doors that are closed 24 hours per day.

Based on these conclusions the research team explored the following hypothesis:

A centrally ducted heating, ventilating, and air-conditioning (HVAC) system with limited distribution and small-diameter (2-in.) ductwork that uses control logic with a combination of intermittent fan operation and highly modulating thermal capacity (including high velocity at peak conditions) will maintain temperature uniformity per the ACCA Manual RS (Rutkowski 1997) while minimizing duct sizes.

From this hypothesis, the team developed the following research questions to be answered by this project:

1. In a low-load home (normalized heating and cooling loads lower than $10 \mathrm{Btu} / \mathrm{h}-\mathrm{ft}^{2}$ of floor area) with ducts in conditioned space, what is the impact of operating a smalldiameter duct system (2-in. diameter) at three different but constant flow rates (which are connected to a variable-capacity heat pump) on temperature variation with time based on ASHRAE Standard 55-2010 (ASHRAE 2010a) on room-to-thermostat uniformity as specified by ACCA Manual RS (Rutkowski 1997), system runtime, and fan efficacy?

2. What is the range of external static pressure required to deliver conditioned air through a small-diameter duct system? How does it compare to that of an HVAC system with traditional duct sizes?

3. What is the cost implication of installing small-diameter ducts in conditioned space compared to traditional duct sizes? 


\section{Research Methods}

Research methods consisted of an independent strategy to answer each research question as stated in Section 1. These strategies were performed in parallel between February 2013 and September 2013. The steps of each strategy are outlined below and are discussed in detail in the subsequent sections.

To answer Research Question 1 and Research Question 2, the team performed the following tasks:

- Characterized the house

- Designed the physical system

- Performed field measurements for short-term analysis periods

- Used measured data as appropriate to assess performance of the HVAC system with respect to applicable standards

- Analyzed the earlier traditional HVAC data collected in the Pittsburgh unoccupied test house

- Compared the data to an existing whole-house TRNSYS (TRNSYS 2012) model.

To answer Research Question 3, the team performed the following tasks:

- Determined the installation costs for small and standard size ductwork

- Determined the builder's perceived cost and aesthetic impacts.

\subsection{Analysis Methods}

The analysis methods used to address Research Question 1 and Research Question 2 are summarized as follows.

For Research Question 1, the team analyzed the thermal uniformity performance of the varied airflow small-duct system in the Pittsburgh, Pennsylvania, unoccupied test house by using relevant comfort criteria. The first thermal comfort criterion was based on the ACCA Manual RS (Rutkowski 1997). This criterion specified a limit of $2^{\circ} \mathrm{F}$ temperature difference between the center of any room and the thermostat location during heating mode and a limit of $3^{\circ} \mathrm{F}$ temperature difference during cooling mode. The second thermal comfort criterion was based on ASHRAE Standard 55-2010 Sections 5.2.5 (Temperature Variations with Time), 7.3.2 (Temperature Cycles and Drifts), and as appropriate 7.4 (Measuring Conditions) (ASHRAE 2010a). An assumption in selecting these two criteria is that maintaining an acceptable indoor temperature represents the minimum requirement that an HVAC system must meet. To provide a reproducible basis for airflow measurement, the team set the fan speed to one of three constant flow rates. The medium fan speed mode represented the right-sized airflow and capacity for the load.

To evaluate these parameters, IBACOS conducted testing from February 2013 through September 2013 in the Pittsburgh, Pennsylvania, unoccupied test house to capture the performance of each airflow rate under heating and cooling weather conditions. 
For Research Question 2, the team took the data for airflow efficacy for the traditionally sized HVAC system from a previous report (Poerschke and Stecher 2014) on the same house using a ground-source heat pump and a standard forced-air system. This approach allowed direct comparison of air distribution methods.

Airflow delivery efficacy and total external static pressure for the small-diameter duct system were calculated from field measurements. Static pressure measurements for the traditional system in the Pittsburgh unoccupied test house were not available. Data collected by several studies looking at the external static pressure of typical field-installed HVAC systems were documented by Proctor and Parker (2010). Those studies indicate that external static pressure of 0.41 to $0.50 \mathrm{in}$. water column could be expected for traditional systems in new-construction single-family homes. Measurements from that study are used here for comparison.

To characterize the Pittsburgh, Pennsylvania, new-construction unoccupied test house, which is shown in Figure 1, the research team performed Building Energy Optimization (BEopt ${ }^{\mathrm{TM}}$ ) modeling (BEopt 2012); the results are presented in Section 3. The garage in this test house is not conditioned.

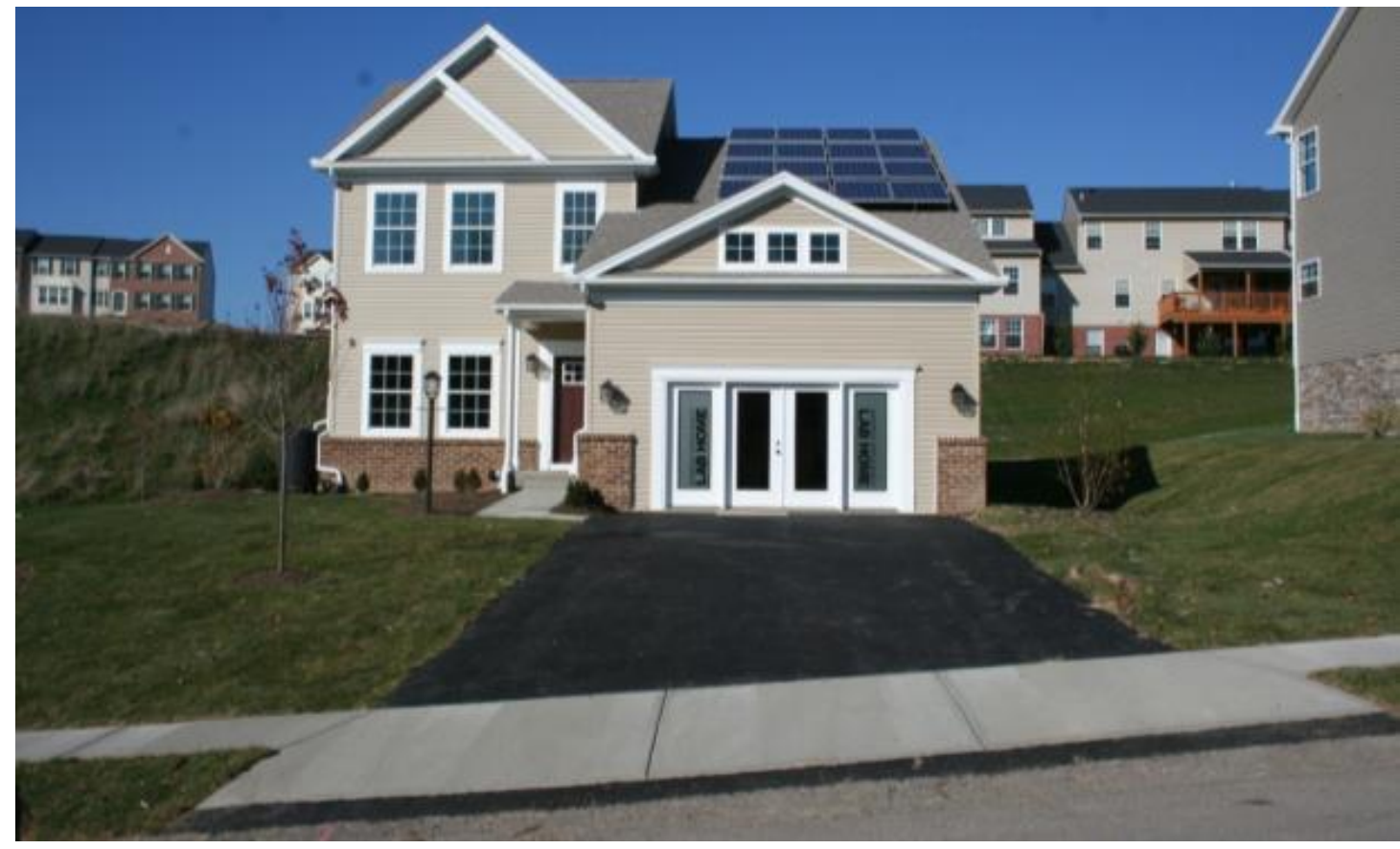

Figure 1. Front view of the Pittsburgh unoccupied test house

Although construction and commissioning of the south-facing, two-story plus basement, 2,772$\mathrm{ft}^{2}$ Pittsburgh unoccupied test house was previously documented by Oberg (2010), a different HVAC system was used for this testing. To reflect the system used in this study, IBACOS performed BEopt modeling with respect to the Building America benchmark (Hendron and Engebrecht 2010) based on the specifications shown in Table 1. 
Table 1. Pittsburgh Test House Specifications

\begin{tabular}{|c|c|}
\hline Assembly & Specifications \\
\hline Concrete Slab & R-10 continuous below slab \\
\hline $\begin{array}{l}\text { Basement/Crawlspace } \\
\text { Walls }\end{array}$ & $\begin{array}{l}\text { R-25 finished portion of basement, } \\
\text { R-19.5 unfinished portion of basement }\end{array}$ \\
\hline $\begin{array}{c}\text { Above-Grade Exterior } \\
\text { Walls }\end{array}$ & $\begin{array}{c}2 \times 4 \text { studs staggered within a } 2 \times 8 \text { wall thickness, R-30 cavity } \\
\text { insulation, R-10 continuous exterior sheathing with recessed } \\
\text { furring strips, } 5 / 8-\text { in. drywall, framing fraction of } 15 \%, \\
\text { whole-wall U-value }=0.024 \mathrm{Btu} / \mathrm{h}-\mathrm{ft}^{2}\end{array}$ \\
\hline Overhanging Floors & N/A \\
\hline $\begin{array}{l}\text { Roof (Location of } \\
\text { Insulation) }\end{array}$ & R- 60 blown insulation in the floor of the vented attic \\
\hline Exterior Doors & $\mathrm{R}-5$ \\
\hline Windows & $306 \mathrm{ft}^{2}, \mathrm{U}$-value $=0.24$, solar heat gain coefficient $=0.22$ \\
\hline Building Airtightness & $0.54 \mathrm{ACH}$ at $50 \mathrm{~Pa}$ actual $(0.6 \mathrm{ACH}$ at $50 \mathrm{~Pa}$ target $)$ \\
\hline Mechanical Ventilation & $\begin{array}{l}\text { Energy recovery ventilator with dedicated single point of } \\
\text { supply/return }\end{array}$ \\
\hline Heating and Cooling & $\begin{array}{l}\text { Air-source heat pump seasonal energy-efficiency ratio of } 21.8 \text {, } \\
\text { heating seasonal performance factor of } 13.6 \text {, Unico } 1218 \text { AHU }\end{array}$ \\
\hline Ductwork & $\begin{array}{c}\text { Insulated } 2 \text {-in.-diameter flex duct; targeted leakage rate of } \\
0 \% \text { leakage to outdoors, and tested total system leakage of } \\
15 \% \text { to indoors and } 0 \% \text { leakage to outdoors }\end{array}$ \\
\hline Water Heater & Assumed to be gas with an energy factor of 0.67 \\
\hline Appliances & $\begin{array}{l}\text { ENERGY STAR }{ }^{\circledR} \text {-rated refrigerator and clothes washer with the } \\
\text { lowest energy consumption ratings from within the builder's } \\
\text { standard product line, dryer matched to washer, builder's standard } \\
\text { ENERGY STAR-rated dishwasher does not have the lowest } \\
\text { energy consumption rating in its class }\end{array}$ \\
\hline $\begin{array}{l}\text { Miscellaneous Electric } \\
\text { Loads }\end{array}$ & No strategies were incorporated to reduce this load area \\
\hline Fluorescent Lighting & $\begin{array}{c}\text { Energy-efficient compact fluorescent lamps and light-emitting } \\
\text { diode fixtures }\end{array}$ \\
\hline Photovoltaic System & 3.8-kW solar photovoltaic array with microinverters \\
\hline
\end{tabular}

$\mathrm{ACH}$ is air changes per hour. AHU is air handling unit. N/A is not applicable.

BEopt modeling indicated a whole-house energy savings of $29.3 \%$ based on the specified thermal enclosure strategy before accounting for photovoltaics. With photovoltaics a savings of $43.8 \%$ was realized. The energy consumption results of the specifications used in the test house (called "My Design" in Figure 2) are compared to energy results of the Building America benchmark specifications of Hendron and Engebrecht (2010) (called "Reference" in Figure 2). 


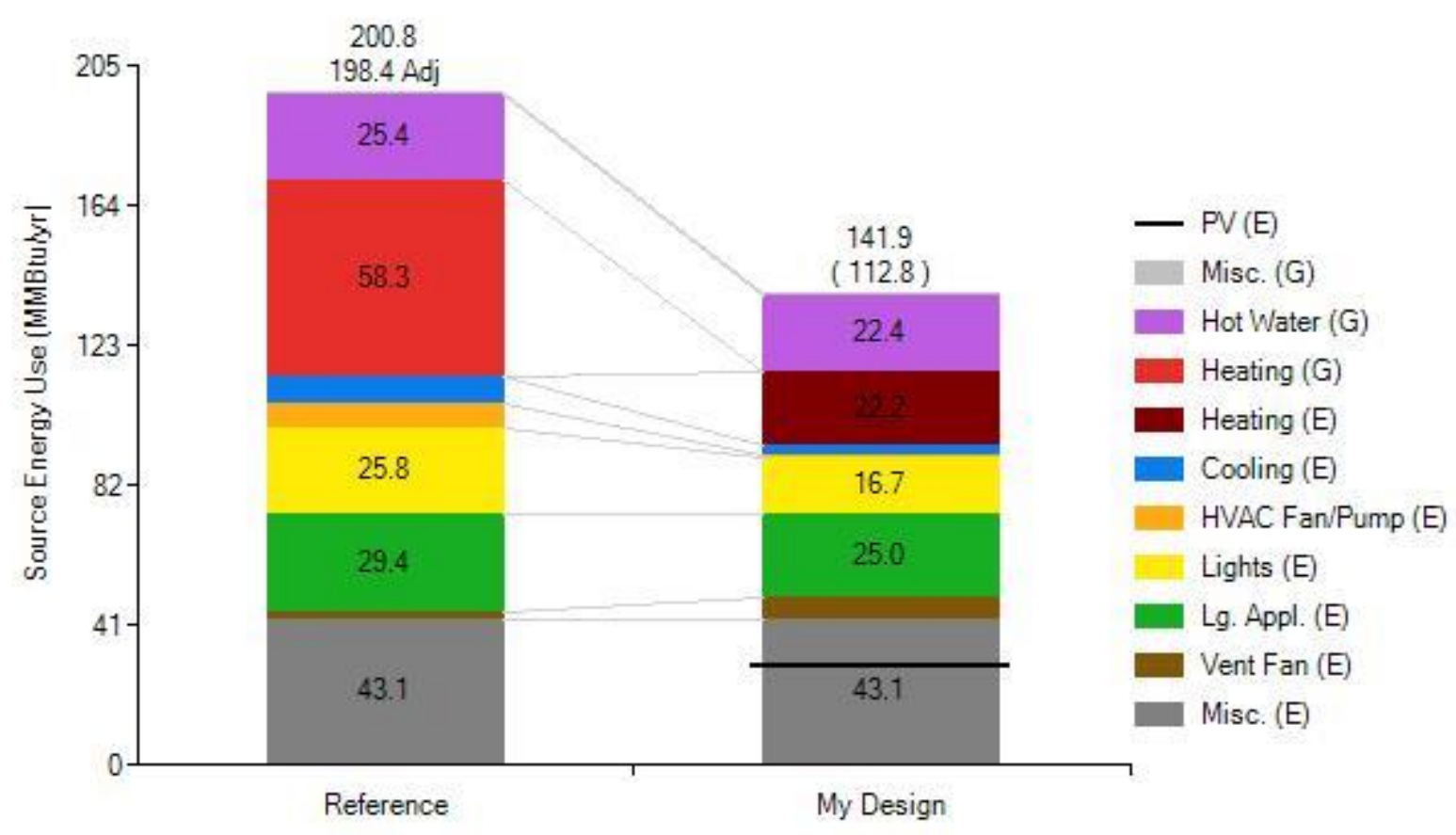

Figure 2. BEopt results

\subsection{System Design}

The small-diameter duct system was designed according to Unico and ACCA methodologyspecifically, the ACCA Manual J (Rutkowski 2006) and the ACCA Manual S (Rutkowski 1995). The system was installed entirely within conditioned space.

\subsubsection{ACCA Manual J Calculations}

To determine the low-load nature of the house, ACCA Manual J (Rutkowski 2006) calculations for peak total and room-by-room design loads were performed based on the specification package shown in Table 1. The calculations were performed using Wrightsoft Right-Suite Universal 8.0.20 software (Wrightsoft 2010).

The resultant whole-house design loads were $18,115 \mathrm{Btu} / \mathrm{h}(5,309 \mathrm{~W})$ in heating and $11,424 \mathrm{Btu} / \mathrm{h}(3,348 \mathrm{~W})$ in cooling. This corresponds to $6.5 \mathrm{Btu} / \mathrm{ft}^{2}-\mathrm{h}\left(20.6 \mathrm{~W} / \mathrm{m}^{2}\right)$ and 4.1 Btu/ $/ \mathrm{ft}^{2}-\mathrm{h}\left(13.0 \mathrm{~W} / \mathrm{m}^{2}\right)$ on a per-unit area basis, respectively. These values are within the lowload threshold of $10 \mathrm{Btu} / \mathrm{ft}^{2}-\mathrm{h}\left(31.5 \mathrm{~W} / \mathrm{m}^{2}\right)$ as previously defined.

\subsubsection{ACCA Manual S Calculations}

Based on the individual room loads and airflow rates shown in Table 2, IBACOS followed ACCA Manual S protocol (Rutkowski 1995) and used the manufacturer's equipment data to select the equipment that was installed in the house. In this case, IBACOS chose a Unico Green Series $1218^{1}$ variable-speed AHU with an electronically commutated fan motor with a refrigerant direct expansion heating and cooling indoor coil (Unico 2011). The delivered airflow range of the AHU is 100 to $450 \mathrm{cfm}$ with an external static pressure of up to $1.5 \mathrm{in}$. water column. Sizing

\footnotetext{
${ }^{1}$ Unico Green Series 1218 variable-speed AHU. St. Louis, MO: Unico. http://www.unicosystem.com/files/3413/8930/2984/Bulletin_20-018_2011-03.pdf.
} 
of the AHU was slightly atypical because Unico recommended an airflow of $250 \mathrm{cfm} / \mathrm{ton}$ compared to a typical 350 to $400 \mathrm{cfm} / \mathrm{ton}$. The AHU was selected based on $250 \mathrm{cfm} / \mathrm{ton}$ and the design static pressure. The AHU was connected to an Argo G50 ${ }^{2}$ air-source heat pump compressor/condenser unit.

Measured airflow values are lower than design values in Table 2. In some cases, the airflow shortage had a negative impact on temperature uniformity. The only ways to have increased airflow to each room would have been to either add an additional 2 -in. duct run in some cases or increase the duct diameter in others. The team decided to monitor the installed performance, maintain the 2-in. duct size, and stay with the original plan to have one duct run to each room.

Table 2. Varied Airflow Small-Duct System Design and Measured Room Airflows at Medium Fan Speed

\begin{tabular}{|c|c|c|c|c|c|c|c|}
\hline & \multicolumn{2}{|c|}{ Heating } & \multicolumn{2}{|c|}{ Cooling } & \multicolumn{3}{|c|}{ Installed } \\
\hline Room & $\begin{array}{c}\text { ACCA } \\
\text { Manual } \\
\text { J Load* } \\
\text { (Btu/h) }\end{array}$ & $\begin{array}{c}\text { Airflow } \\
\text { to } \\
\text { Deliver } \\
\text { Load } \\
\text { (cfm) }\end{array}$ & $\begin{array}{c}\text { ACCA } \\
\text { Manual } \\
\text { J Load* } \\
\text { (Btu/h) }\end{array}$ & $\begin{array}{c}\text { Airflow } \\
\text { to } \\
\text { Deliver } \\
\text { Load } \\
\text { (cfm) }\end{array}$ & $\begin{array}{c}\text { Design } \\
\text { Airflow } \\
\text { (cfm) }\end{array}$ & $\begin{array}{c}\text { Measured } \\
\text { Airflow } \\
\text { (Heating) } \\
\text { (cfm) }\end{array}$ & $\begin{array}{c}\text { Measured } \\
\text { Airflow } \\
\text { (Cooling) } \\
\text { (cfm) }\end{array}$ \\
\hline $\begin{array}{l}\text { Finished } \\
\text { Basement }\end{array}$ & 2,315 & 34 & 758 & 21 & 32 & 21 & 18 \\
\hline $\begin{array}{c}\text { Unfinished } \\
\text { Basement }\end{array}$ & 2,341 & 34 & 666 & 18 & 36 & 20 & 20 \\
\hline $\begin{array}{c}\text { Breakfast } \\
\text { Room }\end{array}$ & 1,242 & 18 & 514 & 14 & 32 & 16 & 16 \\
\hline $\begin{array}{l}\text { Dining } \\
\text { Room }\end{array}$ & 1,071 & 16 & 737 & 20 & 28 & 16 & 14 \\
\hline $\begin{array}{l}\text { Family } \\
\text { Room }\end{array}$ & 2,266 & 33 & 906 & 25 & 36 & 19 & 16 \\
\hline Foyer & 2,208 & 32 & 538 & 15 & 35 & 18 & 17 \\
\hline Bedroom 2 & 1,281 & 19 & 797 & 22 & 35 & 27 & 25 \\
\hline Bedroom 3 & 934 & 14 & 1,768 & 49 & 32 & 27 & 22 \\
\hline Bedroom 4 & 1,606 & 24 & 1,343 & 37 & 31 & 21 & 17 \\
\hline $\begin{array}{c}\text { Master } \\
\text { Bedroom }\end{array}$ & 2,432 & 36 & 1,340 & 37 & 35 & 20 & 17 \\
\hline $\begin{array}{c}\text { Master } \\
\text { Bath }\end{array}$ & 0 & 0 & 0 & 0 & 0 & 0 & 0 \\
\hline Total & 18,115 & 260 & 11,424 & 258 & 260 & 205 & 182 \\
\hline
\end{tabular}

*Rutkowski (2006).

\footnotetext{
${ }^{2}$ Argo G50. Gallarate, Italy: argoclima S.p.A. http://www.argoclima.com/mktg/argo_cat_iseries_2013_EN_w.pdf.
} 


\subsubsection{Distribution System}

To answer Research Question 1, the team operated the AHU at one of three fixed airflow rates during each test with the same air distribution system, which was installed entirely within conditioned space. Thermal output of the heat pump system was modulated by varying the compressor speed and refrigerant flow, depending on the deviation of the thermostat temperature from the set point.

Fan speed was set to a constant value during each test to isolate the impact of airflow. By analyzing the data from a constant flow rate, the team could begin to understand the impact of flow rate on energy performance and comfort under different external conditions. The ideal control algorithm will provide maximum comfort with minimal fan energy.

The team used the Unico manufacturer design guidelines, trunk line takeoff fittings, 2-in.diameter flexible ducts, and supply outlets to size the airflow and ductwork for the varied airflow small-duct system for each room based on the peak load - heating or cooling - calculated by Wrightsoft Right-Suite Universal Version 8.0.20 software (Wrightsoft 2010). When reviewing the loads, the team noticed a large difference between the heating and cooling loads in bedroom 3, as shown in Table 2. To prevent extreme behavior in either mode, the designers specified an airflow rate between the two values.

The ductwork was routed to the first floor via an open wall area in the family room. For the second floor, the supply trunk was routed from the first floor to a trunk line below the secondfloor ceiling with branches routed through openings above each bedroom door. The research focused primarily on the performance of the system on the second floor - to the bedrooms with interior doors closed. Although retrofitted into the existing test house, the small-diameter duct system was installed as a centralized compact duct system with minimal length and bends, which is closer to a typical new-construction installation for low-load homes.

Trunks were sized to fit the fan curve of the AHU. The smallest branch size for the manufacturer's system (2-in. diameter) was larger than necessary for the calculated airflow to be delivered to some of the spaces. To deliver the appropriate amount of airflow to those spaces, a flow restrictor of three possible diameters could be placed where the takeoff meets the main trunk. However, these restrictors are meant for use in one or two ducts in a system. With the restrictors installed on approximately half the branch ducts in the test house, the resulting static pressure for the distribution system exceeded the 1.7-in. water column limit of the AHU. The team removed the restrictors. The resulting design and measured airflows are shown in Table 2, which represents the medium-low speed airflow rate.

Unico circular 2-in.-diameter supply registers with no directional vanes were located high on interior partition walls (Figure 3), which is a well-established method to provide cooling energy. IBACOS determined, through research in cold climates, that this register placement provides equal occupant comfort compared to perimeter floor registers for heating distribution (Rittelmann 2008). Although ACCA Manual T protocol (Rutkowski 2009) was not followed, results of the infrared (IR) flow testing (discussed in the Appendix) show that sufficient throw is possible to reach the exterior wall and to contribute to room air mixing. The single-zone system was controlled via a thermostat located in the first-floor family/dining room area. Figure 4 shows the duct layout. 


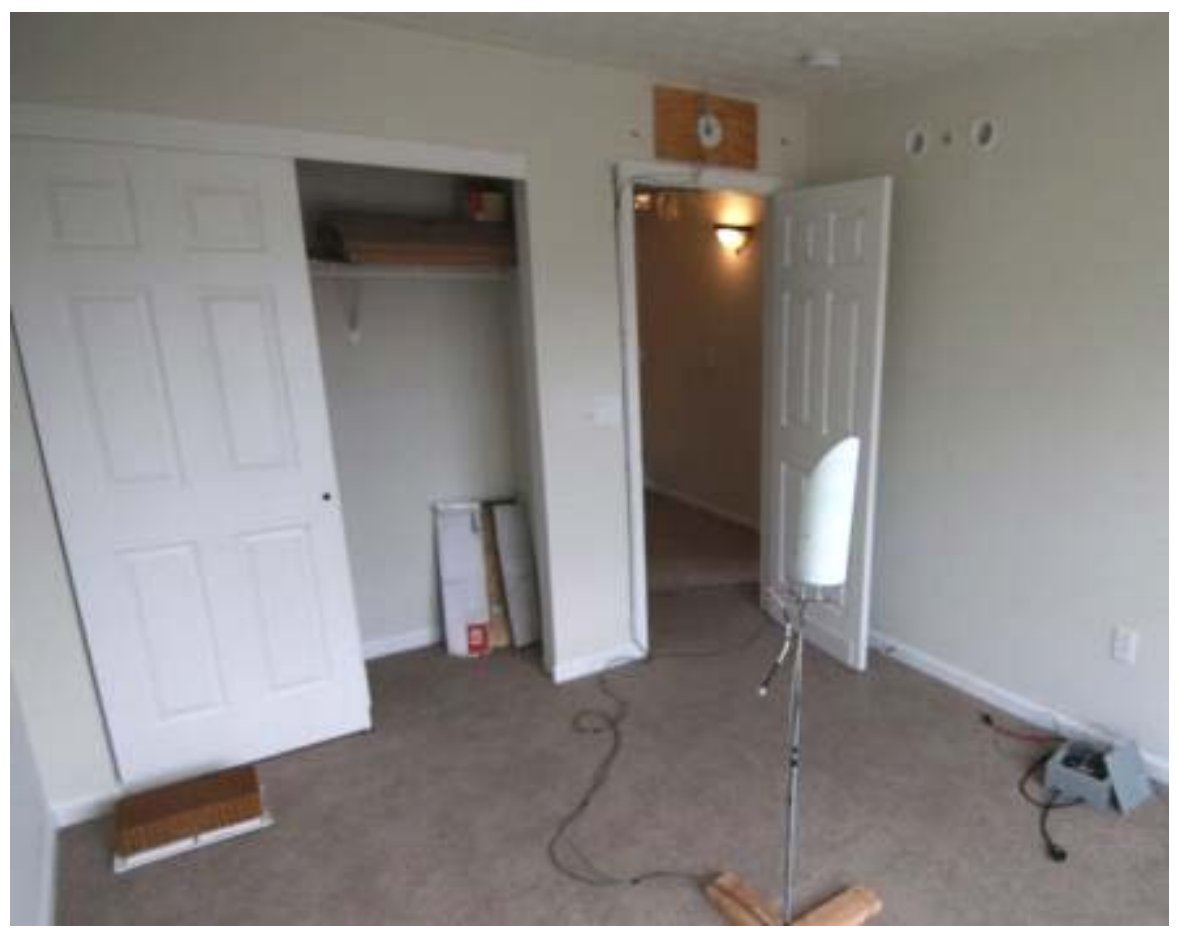

Figure 3. Photograph from the interior of bedroom 3 showing the supply outlet and air temperature measurement stand
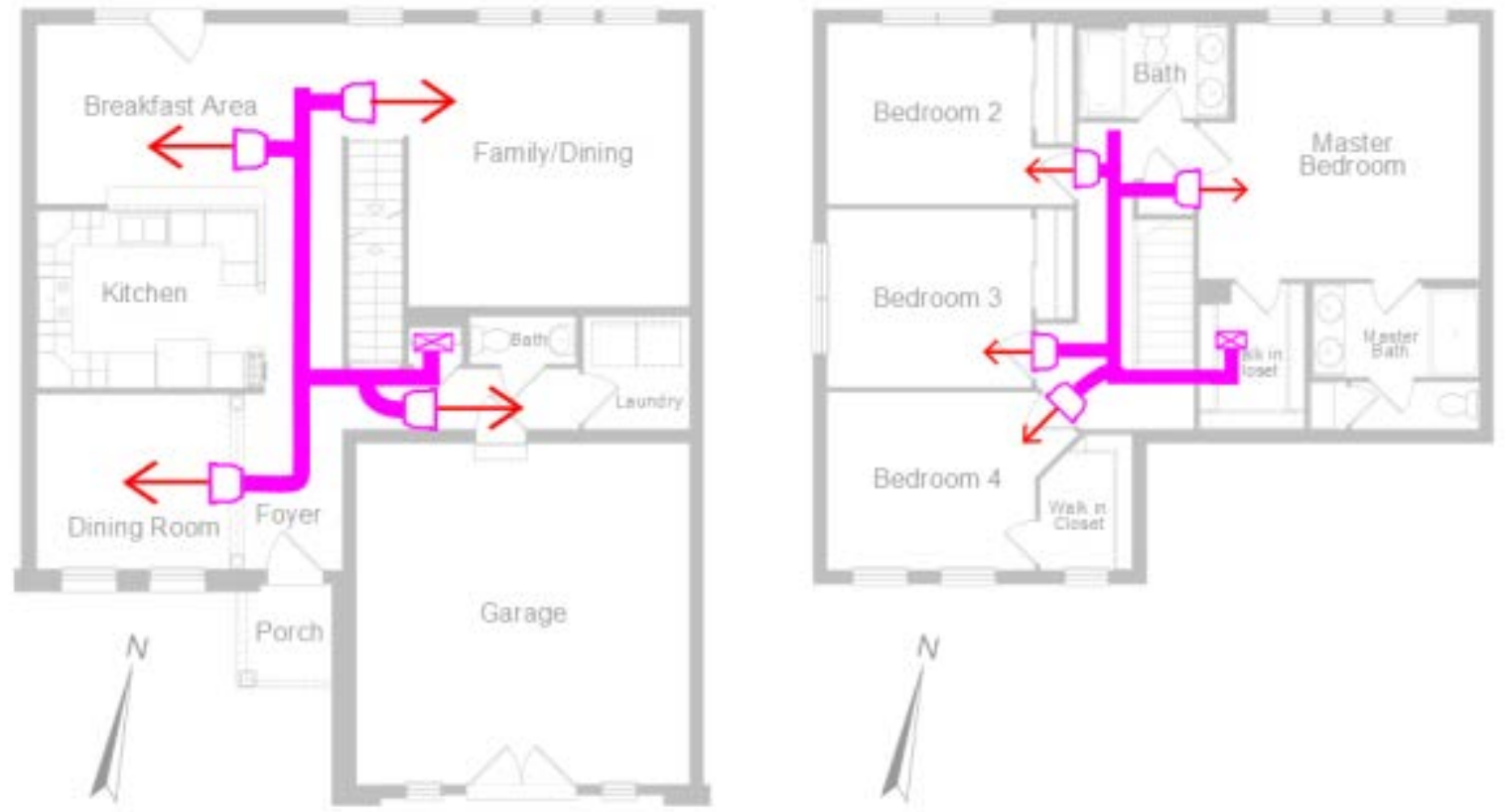

Figure 4. Ductwork layout: first floor (left) and second floor (right); (the partially open door position shown here does not represent the door position used in the house during testing) 
Finally, to accommodate ASHRAE Standard 62.2 requirements (ASHRAE 2010b) an energy recovery ventilator continuously delivered $45 \mathrm{cfm}$ of ventilation air via a single duct to the main living space with a diffuser-type register at the outlet. The energy recovery ventilator exhausted from all bathrooms, the kitchen, and the laundry room.

\subsection{Field Measurements and Short-Term Testing}

A series of short-term tests was conducted from March 2013 through September 2013 to assess system performance and to provide data to use for comparison to the whole-house thermal model. Each short-term test consisted of operating the varied airflow small-duct system at one of the three specified airflow rates and appropriate heating or cooling mode. (Ultimately, only three airflow rates were analyzed.) During these short-term tests, IBACOS measured static pressures, temperature, relative humidity, airflow volume, velocity at the centerline, and electricity consumption to determine thermal comfort and air distribution-related energy consumption. Table 3 shows the types and quantities of each measurement.

Table 3. Measurement Types and Quantities During Short-Term Testing

\begin{tabular}{|c|c|c|}
\hline Measurement & $\begin{array}{l}\text { Equipment } \\
\text { Used }\end{array}$ & $\begin{array}{l}\text { Measurement } \\
\text { Uncertainty } \\
\text { of Equipment* }\end{array}$ \\
\hline $\begin{array}{l}\text { Air Temperature at } 43 \text { in. From } \\
\text { the Floor in Each Room }\end{array}$ & $\begin{array}{c}\text { Fan aspirated Type-T thermocouples } \\
\text { (sensors housed in double wall } \\
\text { measurement shield) }\end{array}$ & $\pm 0.9^{\circ} \mathrm{F}$ \\
\hline $\begin{array}{c}\text { Temperature at Each Supply } \\
\text { Location at Point of Maximum } \\
\text { Velocity }\end{array}$ & $\begin{array}{l}\text { Unshielded Type-T thermocouples with } \\
\text { maximum velocity location determined } \\
\text { by hot wire anemometer trace }\end{array}$ & $\pm 0.9^{\circ} \mathrm{F}$ \\
\hline Temperature at Central Return & Unshielded Type-T thermocouples & $\pm 0.9^{\circ} \mathrm{F}$ \\
\hline $\begin{array}{l}\text { Air Temperature at Each Over- } \\
\text { Door and Bottom-of-Door } \\
\text { Transfer Grille Location }\end{array}$ & Unshielded Type-T thermocouples & $\pm 0.9^{\circ} \mathrm{F}$ \\
\hline $\begin{array}{c}\text { Runtime of HVAC System: } \\
\text { AHU and Heat Pump Outdoor } \\
\text { Unit }\end{array}$ & Continental Control System Wattnode & $0.5 \%$ \\
\hline $\begin{array}{c}\text { Runtime of Energy Recovery } \\
\text { Ventilator }\end{array}$ & Continental Control System Wattnode & $0.5 \%$ \\
\hline $\begin{array}{c}\text { Global Incident Solar Radiation } \\
\text { Onsite }\end{array}$ & $\begin{array}{l}\text { LI-COR } 200 \text { silicon } \\
\text { pyranometer }\end{array}$ & $5.0 \%$ \\
\hline $\begin{array}{c}\text { Outdoor Temperature and } \\
\text { Relative Humidity }\end{array}$ & $\begin{array}{l}\text { Vaisala HMP60 in } \\
\text { shielded enclosure }\end{array}$ & $\begin{array}{l} \pm 0.6^{\circ} \mathrm{F}, \pm 3.0 \% \\
\text { relative humidity }\end{array}$ \\
\hline $\begin{array}{c}\text { Static Pressure at Each } \\
\text { Bedroom Register and AHU } \\
\text { Supply and Return }\end{array}$ & $\begin{array}{l}\text { Pace Scientific P300 } \\
\text { ( } \pm 2 \text { in. water column) }\end{array}$ & $2.0 \%$ \\
\hline $\begin{array}{c}\text { Air Velocity at Each Bedroom } \\
\text { Register; Offet } 1 / 4 \text { in. from } \\
\text { Centerline }\end{array}$ & Elektronik EE575 $(0-20 \mathrm{~m} / \mathrm{s})$ & $6.0 \%$ \\
\hline
\end{tabular}

*The measurement uncertainty listed in this table is the manufacturer's uncertainty. 
The research team performed short-term testing ( 1 to 5 consecutive days) of each of the three airflow rates during the heating and cooling seasons. During each short-term test, the system operated at one of the three fixed airflow rates for the entire test period. Between each test, the system operated in fan-only mode at maximum airflow until temperatures were within $2^{\circ} \mathrm{F}$ to ensure that the house air was well mixed and that temperatures were uniform at the start of the test. Airflow rates were selected to improve the diversity of collected data based on the weather forecast.

The fan speed of the HVAC system was controlled via an IR repeater device connected to a network-enabled laptop. The researchers remotely logged into this laptop to change the system airflow rate at the beginning of each test period. The blower control board automatically adjusted the fan rotation speed to supply the requested volumetric flow rate.

The test standard used in this thermal uniformity analysis specifies a maximum temperature range of $\pm 2^{\circ} \mathrm{F}$ or less over a 15-minute period. Because the range is relatively narrow, IBACOS completed an uncertainty analysis to determine the range of uncertainty. To complete the uncertainty analysis, the team first completed goodness-of-fit tests to determine the distribution of room temperature data. These data were recorded at the Pittsburgh unoccupied test house and included a sensor error with a standard deviation of $0.45^{\circ} \mathrm{F}$. According to the chi-squared test (or $\mathrm{K}-\mathrm{S}$ or $\mathrm{AD}$ ), the room temperature data follow a Gaussian distribution at the $5 \%$ significance level. Next, the team randomly sampled 1 million room temperatures from the Gaussian distribution to create a synthetic set of room temperature data. Finally, the team used the synthetic data to determine the number of events when an incorrect conclusion would be drawn (Type II error). The conclusion of this analysis indicates that the result is correct $88 \%$ of the time.

\subsection{Assessment of House Performance With Respect to Comfort Criteria}

The research team used several methods to assess the thermal uniformity performance of the small-diameter duct system in the Pittsburgh, Pennsylvania, unoccupied test house. Occupant comfort is based on a combination of factors, including occupant clothing and activity level, room air temperature and humidity, mean radiant temperature, and room air velocities (ASHRAE 2010a). In this study, dry bulb temperature alone was the primary consideration because most residential HVAC systems turn on and off based solely on the dry bulb temperature measured by the thermostat. To fail in this area indicates a fundamental failure of the system; to succeed in controlling temperature prompts follow-up questions about performance in other areas (e.g., humidity control) that require different experimental setups. The relevant standards for room air temperature are defined by the ACCA Manual RS (Rutkowski 1997) and ASHRAE Standard 552010 Sections 5.2.5 (Temperature Variations with Time), 7.3.2 (Temperature Cycles and Drifts), and 7.4 (Measuring Conditions) (ASHRAE 2010a).

The ACCA Manual RS (Rutkowski 1997) requires the dry bulb temperature measured at the center of any room of the house to be within $\pm 3^{\circ} \mathrm{F}$ of the thermostat setting during the cooling season and $\pm 2^{\circ} \mathrm{F}$ during the heating season. As described in Section 2.3, there is a $12 \%$ chance of drawing an incorrect conclusion for any single measurement.

ASHRAE Standard 55-2010 Section 5.2.5 (Temperature Variations with Time) (ASHRAE 2010a) outlines three types of temporal temperature fluctuations that affect an occupant's perception of comfort: cyclic variations, drifts, and ramps. Cyclic variations are evaluated when 
the temperature rises and falls during a period of 15 minutes or less, usually when the space conditioning system is cycling. For any 15 -minute period, a change greater than $2^{\circ} \mathrm{F}$ in peak-topeak amplitude is considered uncomfortable. Drift variations are typically evaluated for periods longer than 15 minutes when the space conditioning equipment is not cycling. For any 30 -minute period, a change no greater than $3^{\circ} \mathrm{F}$ is allowed. For any 60 -minute period, a change no greater than $4^{\circ} \mathrm{F}$ change is allowed. For any 120 -minute period, a change no greater than $5^{\circ} \mathrm{F}$ is allowed. For any 240 -minute period, a change no greater than $6^{\circ} \mathrm{F}$ is allowed.

To compare the ASHRAE Standard 55 criteria (ASHRAE 2010a) to the continuously monitored data, the team took the following approach. For each minute of the day, the maximum and minimum temperatures for the previous $15,30,60,120$, and 240 minutes were calculated. If the temperature change was greater than the allowable limit for each interval (i.e., $2^{\circ} \mathrm{F}, 3^{\circ} \mathrm{F}, 4^{\circ} \mathrm{F}, 5^{\circ} \mathrm{F}$, or $6^{\circ} \mathrm{F}$, respectively), that minute was flagged as a failure. For each day, the total failures per interval were then summed.

\subsection{Assessment of Fan Efficacy}

The researchers also evaluated the system based on the fan energy required to deliver the conditioned air. The small-diameter duct system operated with a higher static pressure and a greater temperature change through the coil than the traditional duct system. These two opposing forces can be evaluated in comparison to those of a traditional duct system. To perform this analysis, the total thermal energy (sensible and latent) added to or removed from the airstream (return to supply) was calculated for each minute of measured data when the fan was operational.

\subsubsection{Commissioning Overview}

To commission the Pittsburgh, Pennsylvania, unoccupied test house and varied airflow volume small-diameter duct HVAC system for testing duty, the research team performed the following tasks for each of the three airflow rates used in the long-term testing:

- Measured airflow at each supply register

- Measured whole-system airflow at the return plenum

- Measured air temperature and velocity at each supply register

- Measured sound levels

- Visualized IR flow

- Measured net duct leakage to the inside

- Measured ventilation supply and exhaust rates

- Measured whole-house air leakage.

The details of each of these tests are discussed in the following sections.

\subsubsection{Measured Airflow at Each Supply Register}

The three AHU fan speeds are low, medium, and high. The research team measured the airflow from each supply register at each blower speed in both heating and cooling modes using an 
Energy Conservatory calibrated powered flow hood. ${ }^{3}$ At the very low supply register flow rates using the low fan speed, a bag test ${ }^{4}$ was thought to be more accurate and was performed instead.

For some registers, the team could not create a seal around the flow hood perimeter because of insufficient flat wall area. In those cases, the opening of the flow hood was made smaller using duct mask so that only the register face would fit through the opening.

Measured airflow rates at all three fan speeds under heating mode and cooling mode are shown in Table 4 and Table 5, respectively.

Table 4. Field Measured Supply Airflow Rate at Each Register-Heating Mode

\begin{tabular}{c|c|c|c}
\hline Room & $\begin{array}{c}\text { Low Speed } \\
\text { Measured } \\
\text { (cfm) }\end{array}$ & $\begin{array}{c}\text { Medium Speed } \\
\text { Measured } \\
\text { (cfm) }\end{array}$ & $\begin{array}{c}\text { High Speed } \\
\text { Measured } \\
\text { (cfm) }\end{array}$ \\
\hline Finished Basement & 12 & 24 & 39 \\
\hline Unfinished Basement & 13 & 26 & 34 \\
\hline Living Room & 11 & 25 & 32 \\
\hline Dining Room & 12 & 22 & 38 \\
Hall & 10 & 17 & 29 \\
Bedroom 2 & 11 & 16 & 40 \\
Bedroom 3 & 18 & 36 & 61 \\
Bedroom 4 & 18 & 37 & 52 \\
Master Bedroom & 13 & 29 & 44 \\
System Total & 14 & 23 & 40 \\
\hline
\end{tabular}

\footnotetext{
${ }^{3}$ The Energy Conservatory, Minneapolis, MN. http://www.energyconservatory.com/products/duct-blaster\%C2\%AEsystems-and-accessories/flowblaster\%C $2 \%$ AE-capture-hood-accessory.

${ }^{4}$ The Trash Bag Method. Field Test Best Practices. Golden, CO: National Renewable Energy Laboratory. https://buildingsfieldtest.nrel.gov/the trash_bag_method.
} 
Table 5. Field Measured Supply Airflow Rate at Each Register-Cooling Mode

\begin{tabular}{c|c|c|c}
\hline Room & $\begin{array}{c}\text { Low Speed } \\
\text { Measured } \\
\text { (cfm) }\end{array}$ & $\begin{array}{c}\text { Medium Speed } \\
\text { Measured } \\
\text { (cfm) }\end{array}$ & $\begin{array}{c}\text { High Speed } \\
\text { Measured } \\
\text { (cfm) }\end{array}$ \\
\hline Finished Basement & 12 & 25 & 44 \\
\hline Unfinished Basement & 13 & 27 & 47 \\
\hline Living Room & 10 & 24 & 28 \\
Dining Room & 12 & 27 & 44 \\
Hall & 9 & 18 & 21 \\
Bedroom 2 & 11 & 17 & 36 \\
Bedroom 3 & 16 & 32 & 63 \\
Bedroom 4 & 15 & 29 & 57 \\
Master Bedroom & 12 & 27 & 47 \\
System Total & 11 & 21 & $\mathbf{4 2 7}$ \\
\hline
\end{tabular}

The research team attempted to balance the small-diameter duct system but found that impossible via the manufacturer-provided airflow reducers because that raised the static pressure enough to unacceptably reduce the total system airflow. Clearly, the master bedroom and bedroom 4 had lower than designed airflow rates. Because of problems with measuring wholesystem airflow at the return plenum (see Section 2.5.3), the measured total system airflow values in Table 4 and Table 5 are the sums of the individual room values.

\subsubsection{Whole-System Airflow Measured at the Return Plenum}

The research team attempted to measure the airflow at the return plenum using an Energy Conservatory True-Flow ${ }^{5}$ plate. However, that approach does not work with variable-speed AHUs that are programmed to ramp up airflow when restriction is added. Therefore, the restriction caused by the flow plate made the AHU ramp up in speed, which led to erroneous results. Thus, no whole-system airflow measurement was performed and the sum of the individual measurements was used.

\subsubsection{Measured Supply Air Velocity and Temperature at Three Fan Speeds}

To observe any differences between the supply air velocity and temperature that a field technician might measure and what the long-term test equipment measured, the team used a TSI VelociCheck Hotwire Anemometer ${ }^{6}$ to measure the temperature and velocity of the supply air at all three fan speeds at the center of the supply outlet (see Figure 5).

\footnotetext{
${ }^{5}$ True-Flow Air Handler Flow Meter. Minneapolis, MN: The Energy Conservatory. http://www.energyconservatory.com/products/trueflow\%C2\%AE-air-handler-flow-meter.

${ }^{6}$ TSI VelociCheck Hotwire Anemometer. Shoreview, MN: TSI, Inc. (discontinued).
} 


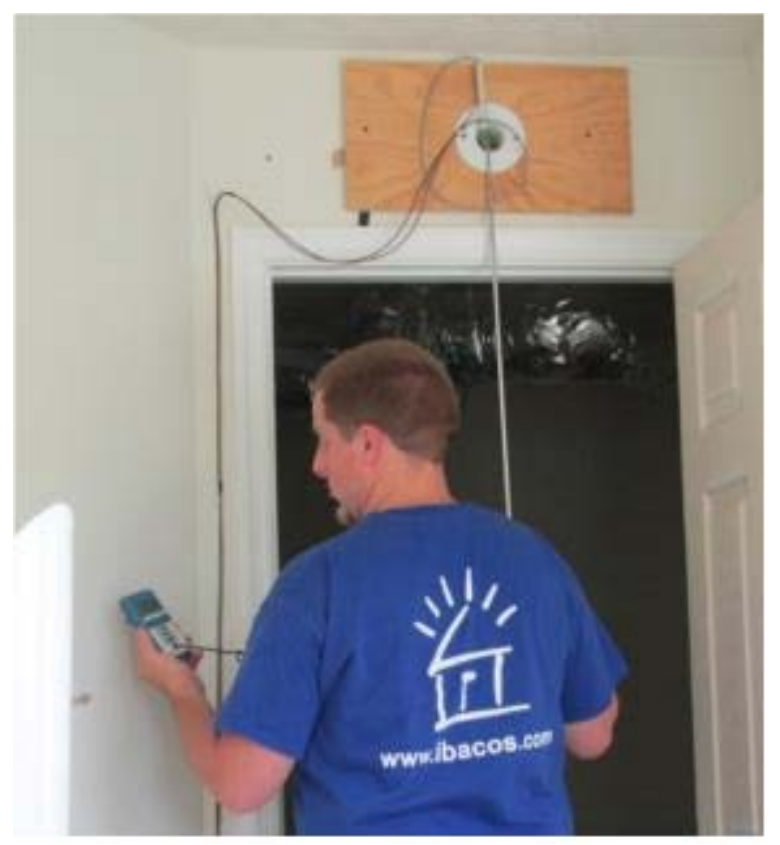

Figure 5. Measuring airflow rate using a hot wire anemometer

The VelociCheck remained in place for 30 seconds for each temperature and velocity measurement. The results from the VelociCheck were compared to measurements taken by the data-logger-connected temperature and flow measurements for long-term testing (see Table 6 and Table 7). All measured velocities met minimum ACCA Manual T standards (Rutkowski 2009b) in both heating and cooling modes. Differences in velocity of up to $23 \%$ were observed between the VelociCheck and long-term data-logger-based velocity measurement. Because the datalogger-based measurement is located slightly off center on the register, the researchers expected the VelociCheck to read consistently higher. Although many VelociCheck measurements were higher than the data-logger-based measurement, no clear trend was found because in some cases the values were similar to one another or the data-logger-based measurement was higher than the VelociCheck measurement. The turbulent discharge from the supply outlet may have caused this. Temperature measurements of the VelociCheck and data logger were within 3\%. 
Table 6. VelociCheck and Data-Logger Recorded Supply Air Velocity and Temperature in Cooling Mode at Three Fan Speeds

\begin{tabular}{|c|c|c|c|c|c|}
\hline Cooling & \multirow[b]{2}{*}{ Room } & \multicolumn{2}{|c|}{ Air Velocity (fpm) } & \multicolumn{2}{|c|}{ Temperature $\left({ }^{\circ} \mathbf{F}\right)$} \\
\hline $\begin{array}{c}\text { Fan } \\
\text { Speed }\end{array}$ & & VelociCheck & $\begin{array}{c}\text { Data } \\
\text { Logger }\end{array}$ & VelociCheck & $\begin{array}{c}\text { Data } \\
\text { Logger }\end{array}$ \\
\hline \multirow{4}{*}{ Low } & Master bedroom & 690 & 470 & 58 & 56 \\
\hline & Bedroom 2 & 960 & 880 & 56 & 57 \\
\hline & Bedroom 3 & 910 & 793 & 56 & 57 \\
\hline & Bedroom 4 & 790 & 807 & 57 & 58 \\
\hline \multirow{4}{*}{ Medium } & Master bedroom & 1,290 & 738 & 57 & 55 \\
\hline & Bedroom 2 & 1,810 & 1,502 & 57 & 56 \\
\hline & Bedroom 3 & 1,670 & 1,451 & 57 & 57 \\
\hline & Bedroom 4 & 1,450 & 1,488 & 58 & 58 \\
\hline \multirow{4}{*}{ High } & Master bedroom & 2,390 & 1,283 & 59 & 59 \\
\hline & Bedroom 2 & 3,220 & 2,020 & 58 & 60 \\
\hline & Bedroom 3 & 2,890 & 2,016 & 58 & 57 \\
\hline & Bedroom 4 & 2,450 & 2,018 & 59 & 58 \\
\hline
\end{tabular}

Table 7. VelociCheck and Data-Logger Recorded Supply Air Velocity and Temperature in Heating Mode at Three Fan Speeds

\begin{tabular}{c|c|c|c|c|c}
\hline Heating & \multirow{2}{*}{$\begin{array}{c}\text { Fan } \\
\text { Speed }\end{array}$} & Room & \multicolumn{2}{|c|}{ Air Velocity (fpm) } & \multicolumn{2}{c}{ Temperature $\left({ }^{\circ} \mathbf{F}\right)$} \\
\cline { 3 - 5 } & & VelociCheck & $\begin{array}{c}\text { Data } \\
\text { Logger }\end{array}$ & VelociCheck & $\begin{array}{c}\text { Data } \\
\text { Logger }\end{array}$ \\
\hline \multirow{4}{*}{ Low } & Master bedroom & 580 & 683 & 110 & 111 \\
\cline { 2 - 5 } & Bedroom 2 & 850 & 1,148 & 111 & 113 \\
& Bedroom 3 & 750 & 1,041 & 114 & 119 \\
\cline { 2 - 5 } & Bedroom 4 & 610 & 892 & 112 & 115 \\
& Master bedroom & 1,040 & 1,388 & 113 & 112 \\
\cline { 2 - 5 } Medium & Bedroom 2 & 1,560 & 2,006 & 113 & 114 \\
& Bedroom 3 & 1,410 & 1,722 & 116 & 119 \\
\cline { 2 - 5 } & Bedroom 4 & 1,170 & 1,531 & 114 & 115 \\
& Master bedroom & 1,910 & 1,870 & 112 & 110 \\
\cline { 2 - 5 } & Bedroom 2 & 2,610 & 2,018 & 112 & 112 \\
\cline { 2 - 5 } & Bedroom 3 & 2,350 & 2,020 & 113 & 111 \\
\cline { 2 - 5 } & Bedroom 4 & 1,980 & 2,020 & 114 & 112 \\
\hline
\end{tabular}

\subsubsection{Measured Sound Levels}

As part of the commissioning process, the researchers recorded the sound levels during system operation at high fan speed. During these tests, the noise-producing anemometers used to measure the velocity during long-term testing were removed. An Extech data logging sound level 
meter $^{7}$ was attached to a tripod positioned $3 \mathrm{ft}$ horizontally from the outlet at $67 \mathrm{in}$. vertically from the finished floor, with the sensor pointed at the wall directly below the outlet. Measured sound levels ranged from 38.2 decibels in the master bedroom to 46.6 decibels in bedroom 2 . Because these levels were close to background levels, no significant conclusions could be drawn from these measurements.

\subsubsection{Duct Air Leakage}

After the ductwork and mechanical equipment were installed, the research team used a Duct Blaster ${ }^{8}$ to determine the total air leakage from the air distribution ductwork. To determine the amount of air leakage from the ductwork to the outdoors the team performed duct leakage testing in conjunction with the blower door test.

The 2012 International Energy Conservation Code (IECC 2012) requires the duct system to be no more than $4 \mathrm{cfm} / 100 \mathrm{ft}^{2}$ of conditioned floor area. The installed duct system meets this requirement at $1.2 \mathrm{cfm} / 100 \mathrm{ft}^{2}$ of conditioned floor area. Total air leakage from the distribution system was determined as a percentage of the total system airflow. Table 8 shows the results. Leakage was noted where the AHU connects to the ductwork and at the access panels on the AHU. Silicon sealant was used to seal the ductwork connection.

Table 8. Comparison of System Leakage

\begin{tabular}{c|c}
\hline & Test House \\
\hline Total System Leakage & $31 \mathrm{cfm} 25$ \\
Percentage of Total System Leakage & $11.9 \%$ \\
Leakage to Outside & $0 \mathrm{cfm} 25$ \\
\hline Percentage of Leakage to Outside & $0.0 \%$ \\
\hline
\end{tabular}

The team also observed leakage along the trunk leading to the second floor; however, the specific location was impossible to determine because insulation covered the duct. During installation, the round metal ductwork trunks were sealed with mastic, and then a sleeve of insulation was slid over the trunk before the branch takeoffs were attached. Although practical for the installer, this assembly method makes it difficult to locate and seal leaks in the trunks without cutting open the insulation sleeve in multiple locations. Furthermore, the acoustical ductwork used for the branches requires care during installation to ensure the outer lining is not punctured. Partly because the location of the ductwork was entirely within conditioned space, no leakage occurred to the outdoors.

\subsubsection{Whole-House Air Infiltration}

After the test HVAC system was installed, the team conducted a blower door test to evaluate the airtightness performance of the building enclosure (see Figure 6). The test measured the number of house air changes per hour under $50 \mathrm{~Pa}$ negative pressure.

\footnotetext{
${ }^{7}$ Data Logging Sound Level Meter. Nashua, NH: Extech Instruments. http://www.extech.com/instruments/product.asp?catid=18\&prodid=241.

${ }^{8}$ Duct Blaster. Minneapolis, MN: The Energy Conservatory. http://www.energyconservatory.com/products/ductblaster $\% \mathrm{C} 2 \% \mathrm{AE}$-systems-and-accessories.
} 


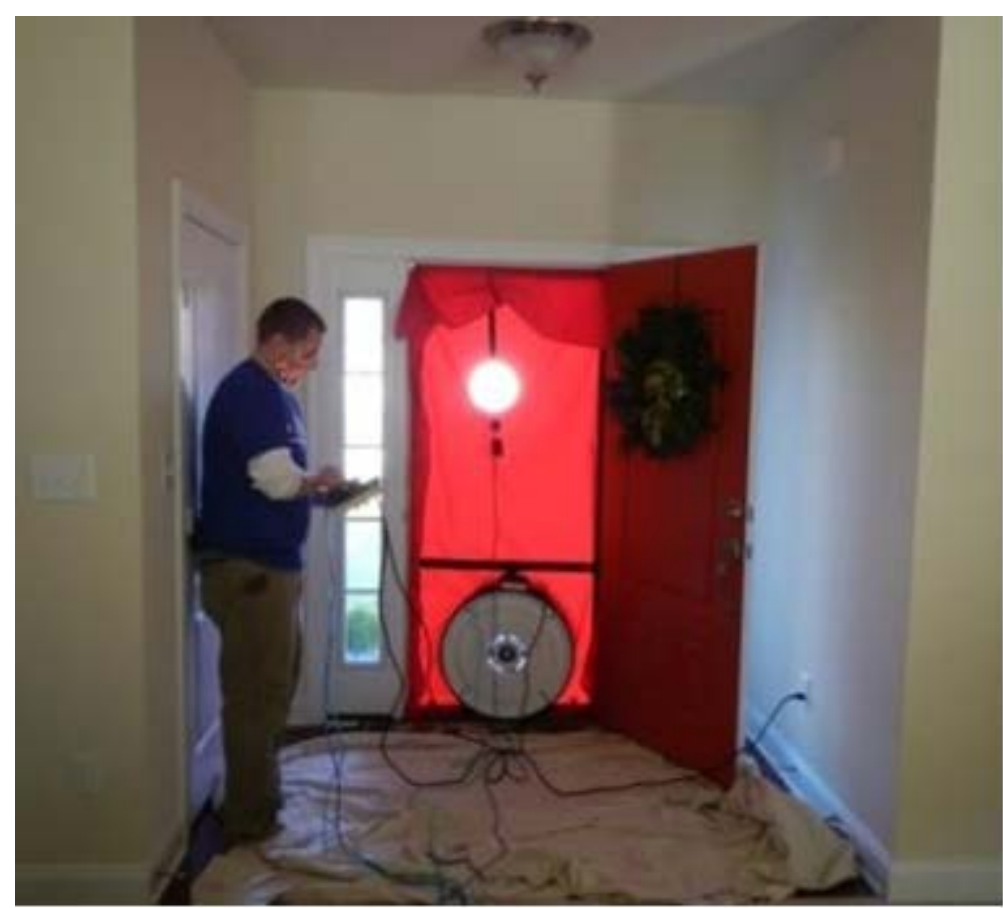

Figure 6. Typical blower door testing (not the actual test house)

During the testing, the outdoor conditions were $80^{\circ} \mathrm{F}, 55 \%$ relative humidity and $1.9-\mathrm{mph}$ wind speed from the west. Table 9 shows the test results.

Table 9. Comparison of Whole-House Infiltration

\begin{tabular}{c|c}
\hline & Test House \\
\hline House Size & $1,715 \mathrm{ft}^{2}$ finished floor area \\
Infiltration & $397 \mathrm{cfm} 50$ \\
& $0.86 \mathrm{ACH} 50$ \\
\hline
\end{tabular}




\section{Results}

Data collected for this project are summarized in several sections. The calculated results from the ACCA spatial and ASHRAE temporal temperature uniformity standards are presented first. Temperature and system runtime data are presented next to provide a basis for discussing the calculated comfort standards data. Table 10 shows a summary of the data analysis methods used by the team.

Table 10. Summary of Data Analysis Methods

\begin{tabular}{c|c|c}
\hline Analysis & Range Analyzed & Data Type \\
\hline ASHRAE 55-2010 Section 5.2.5 & Representative days & Measured \\
Temperature Variations with Time & & \\
(ASHRAE 2010a) & Representative days & Measured \\
ACCA Manual RS (Rutkowski 1997) & Representative days & Measured \\
\hline
\end{tabular}

Representative days were selected by choosing from the period of available days in which weather conditions were correct and the system was operating in the desired mode. A total of 6 days were selected (see Figure 7). Between June 7, 2013, and July 11, 2013, the AHU controller module was not working; the system was not operational until a new module was delivered and installed.

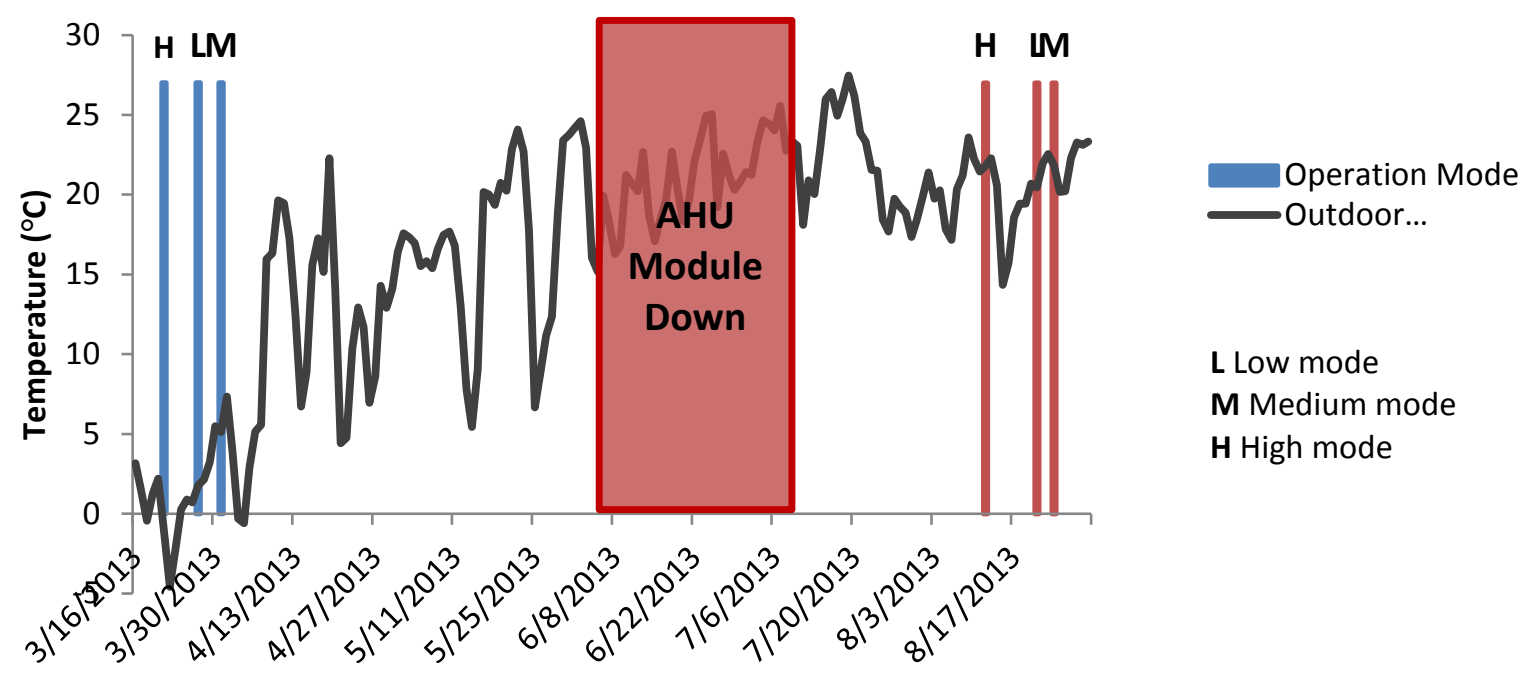

Figure 7. Selection of representative days

\subsection{ASHRAE Standard 55-2010 Temperature Variations With Time}

Results from the ASHRAE Standard 55-2010 (ASHRAE 2010a) cyclic and drift temperature variation analysis are shown in Table 11 for the heating season tests. Percentage values in the table are based on the percentage of minutes in each day that a particular room failed in each given airflow mode to have less than the cyclic temperature variation limit in the given time period (shown in minutes). For example, the percentages listed in the row labeled " 15 " indicate a 
cycling temperature swing of $2^{\circ} \mathrm{F}$ or more in 15 minutes. The other longer-term failure mode descriptions are explained in Section 2.4.

During cooling mode all airflow modes provided a $100 \%$ passing rate for temperature variation with time for the entire house. A separate table for these data is not included. High-speed fan heating-mode tests showed $7 \%-15 \%$ failure rates over 15 -minute to 4 -hour time periods. These were caused primarily by condenser coil defrost cycles. This was most evident with high fan speed because the house cooled faster during the same defrosting time.

Table 11. Heating Season Test Results Based on ASHRAE Standard 55-2010 Section 5.2.5, ${ }^{*}$ Cyclic and Drift Temperature Variation Limits

\begin{tabular}{|c|c|c|c|c|c|c|c|c|c|c|}
\hline & 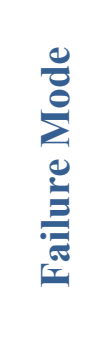 & $\stackrel{b 0}{. \Xi}$ & 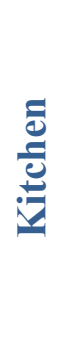 & 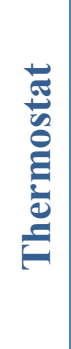 & 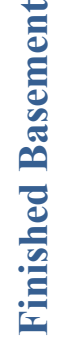 & 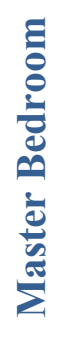 & 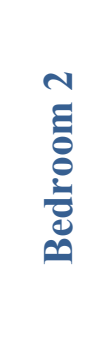 & 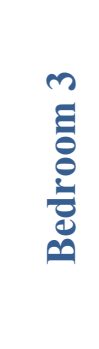 & 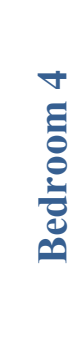 & $\begin{array}{l}\overline{\bar{\sigma}} \\
\frac{\pi}{\pi} \\
\frac{0}{0} \\
\frac{0}{2} \\
\bar{b}\end{array}$ \\
\hline \multirow{5}{*}{ Low Fan } & 15 & 0 & 0 & 0 & 0 & 0 & 0 & 0 & 0 & 0 \\
\hline & 30 & 0 & 0 & 0 & 0 & 0 & 0 & 0 & 0 & 0 \\
\hline & 60 & 0 & 0 & 0 & 0 & 0 & 0 & 0 & 0 & 0 \\
\hline & 120 & 0 & 0 & 0 & 0 & 0 & 0 & 0 & 0 & 0 \\
\hline & 240 & 0 & 0 & 0 & 0 & 0 & 0 & 0 & 0 & 0 \\
\hline \multirow{5}{*}{ Medium Fan } & 15 & 0 & 0 & 0 & 0 & 0 & 0 & 0 & 0 & 0 \\
\hline & 30 & 0 & 0 & 0 & 0 & 0 & 0 & 0 & 0 & 0 \\
\hline & 60 & 0 & 0 & 0 & 0 & 0 & 0 & 0 & 0 & 0 \\
\hline & 120 & 0 & 0 & 0 & 0 & 0 & 0 & 0 & 0 & 0 \\
\hline & 240 & 0 & 0 & 0 & 0 & 0 & 0 & 0 & 0 & 0 \\
\hline \multirow{5}{*}{ High Fan } & 15 & 0 & 0 & 0 & 0 & 0 & $7 \%$ & $8 \%$ & $1 \%$ & 0 \\
\hline & 30 & 0 & 0 & 0 & 0 & 0 & $4 \%$ & $7 \%$ & 0 & 0 \\
\hline & 60 & 0 & 0 & 0 & 0 & 0 & $4 \%$ & $6 \%$ & 0 & 0 \\
\hline & 120 & 0 & 0 & 0 & 0 & 0 & $10 \%$ & $10 \%$ & 0 & 0 \\
\hline & 240 & 0 & 0 & 0 & 0 & 0 & $15 \%$ & $13 \%$ & 0 & 0 \\
\hline
\end{tabular}

\section{* ASHRAE (2010a).}

\subsection{ACCA Manual RS Room-to-Thermostat Temperature Uniformity}

Results from the ACCA Manual RS (Rutkowski 1997) analysis using the methodology described in Section 2.4 are shown in Table 12, which provides a summary of the analysis. The higher the percentage shown, the more time a room deviated from the set point, providing an indication of discomfort. Also included in this table is the average outdoor temperature for the day the analysis was performed. In addition to the ACCA Manual RS results, the measured airflow as a percentage of the ACCA Manual J design airflow (Rutkowski 2006) is presented in this table in the last two rows. Values greater than 100\% represent excess airflow. Values less than 100\% represent insufficient airflow to meet peak load. 
Table 12. ACCA Manual RS Temperature Deviation Failure Rate

\begin{tabular}{|c|c|c|c|c|c|c|c|c|c|c|c|c|c|}
\hline & & 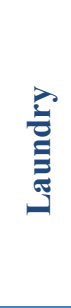 & 葛 & $\frac{\vec{E}}{\frac{\vec{w}}{\pi}}$ & בְב. & 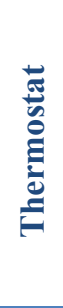 & 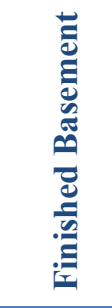 & 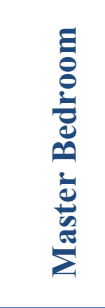 & 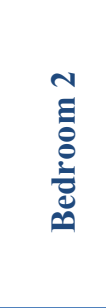 & 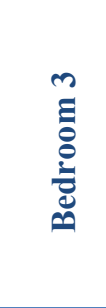 & 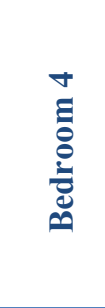 & 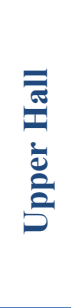 & 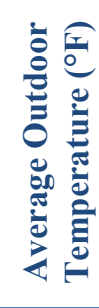 \\
\hline \multirow{3}{*}{ 胥 } & Low & 0 & 0 & 0 & 0 & 0 & $100 \%$ & $100 \%$ & 0 & $2 \%$ & $65 \%$ & 0 & 35.8 \\
\hline & Medium & 0 & 0 & 0 & 0 & 0 & $100 \%$ & $100 \%$ & 0 & 0 & 0 & 0 & 45.2 \\
\hline & High & 0 & 0 & 0 & 0 & 0 & $100 \%$ & $100 \%$ & $10 \%$ & $28 \%$ & $21 \%$ & 0 & 23.8 \\
\hline \multirow{3}{*}{ ن. } & Low & 0 & 0 & 0 & 0 & 0 & 0 & 0 & 0 & $13 \%$ & $40 \%$ & 0 & 71.5 \\
\hline & Medium & 0 & 0 & 0 & 0 & 0 & 0 & 0 & 0 & $18 \%$ & $37 \%$ & 0 & 68.3 \\
\hline & High & 0 & 0 & 0 & 0 & 0 & 0 & 0 & 0 & $3 \%$ & $18 \%$ & 0 & 72.1 \\
\hline $\mathbf{H}^{*}$ & Medium & & & & & & & $64 \%$ & $189 \%$ & $264 \%$ & $120 \%$ & & \\
\hline$C^{*}$ & Medium & & & & & & & $57 \%$ & $145 \%$ & $59 \%$ & $73 \%$ & & \\
\hline
\end{tabular}

* Medium-speed delivered airflow as a percentage of the ACCA Manual J design airflow (Rutkowski 2006).

\subsection{System Runtime and Temperature Data}

Figure 8 through Figure 13 display the system runtime and temperature data in heating and cooling modes. The temperature variation from thermostat value is calculated based on the roomto-thermostat temperature difference. For convenience, the $\pm 2^{\circ} \mathrm{F}$ and $\pm 3^{\circ} \mathrm{F}$ comfort criteria are displayed on each plot. Any period in which conditioned space deviates from this boundary does not conform to the ACCA Manual RS comfort standards for room-to-thermostat temperature uniformity (Rutkowski 1997).

Measured outdoor temperature and thermostat temperature values are plotted in addition to the room temperature deviation from thermostat. The AHU kilowatt draw and the condenser kilowatt draw also are presented to aid in discussing system performance.

A set of cold cloudy days was chosen for the heating mode displayed in Figure 8 through Figure 10. A set of hot sunny days was chosen to represent cooling mode data displayed in Figure 11 through Figure 13. These days align with the analysis presented in the ACCA and ASHRAE results sections. 


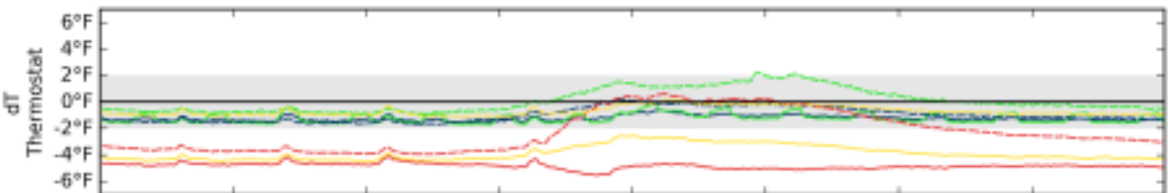

- Dining Bedroom3

- Kitchen -- Bedroom4

- Finish日asement UpperHall

MasterBedroom - Thermostat

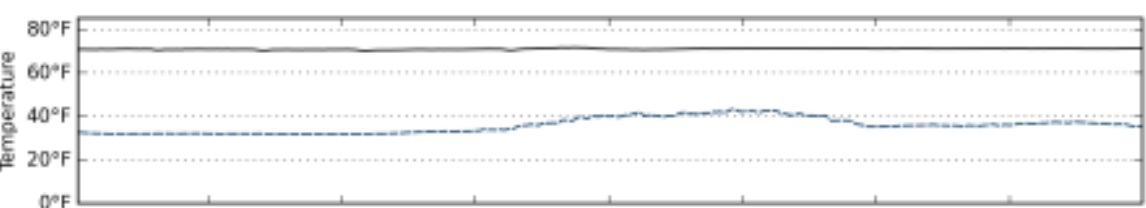

-.- Bedroom2

-- Outdoor

- Thermostat

0.060

$\begin{array}{r}0.065 \\ 0.030 \\ \hline\end{array}$

0.015
0.000

- AirHandler

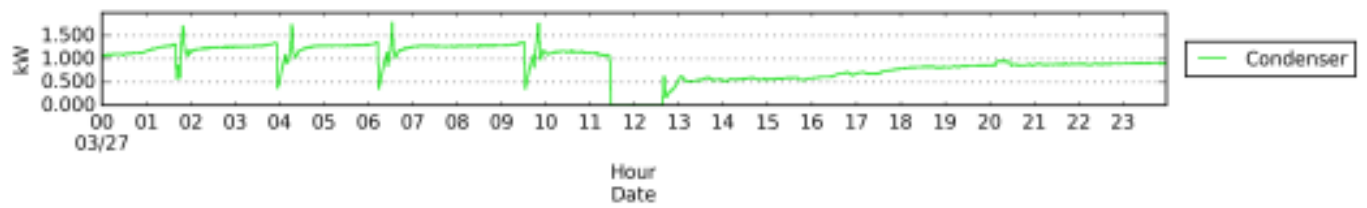

Figure 8. Heating low fan speed

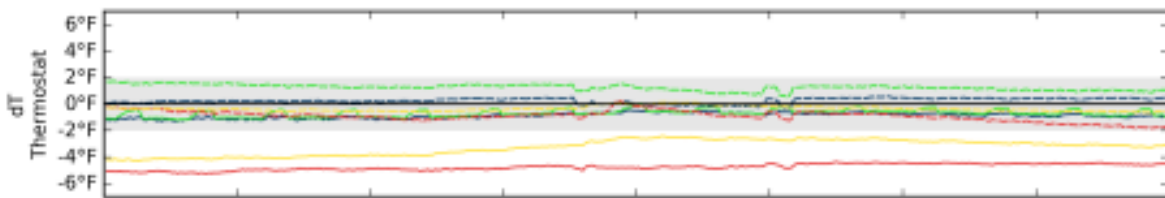

- Dining Bedroom3

- Kitchen -- Bedroom4

- FinishHasement - UpperHall

MasterBedroom - Thermostat

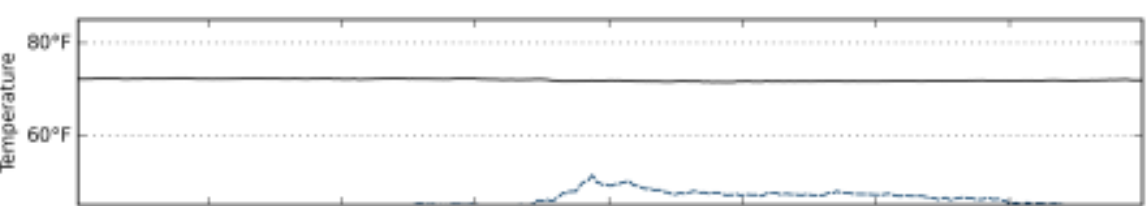

--. Bedroom2

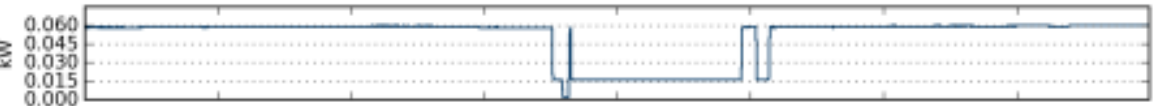

AirHandler

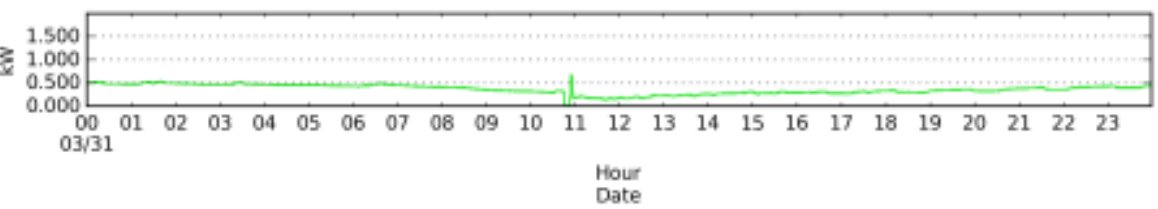

Condenser

Figure 9. Heating medium fan speed 


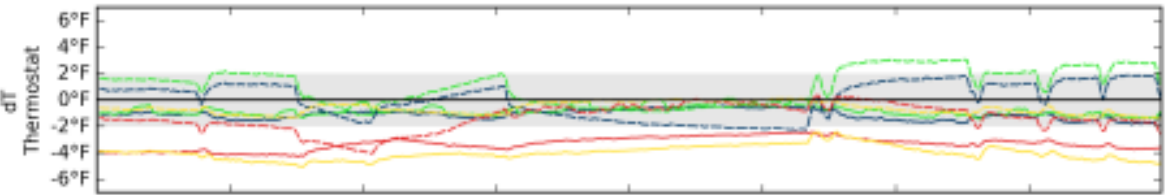

- Dining Bedraom3

- Kitchen

--. Bedroom4

- FinishHasement

UpperHall

MasterBedroom - Thermostat

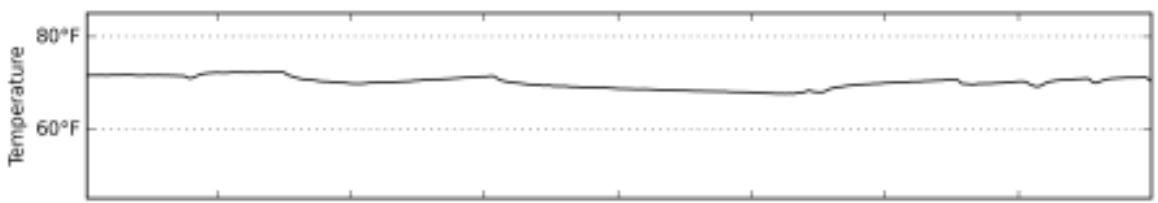

-. Bedroomz

\section{-- Outdoor}

- Thermostat

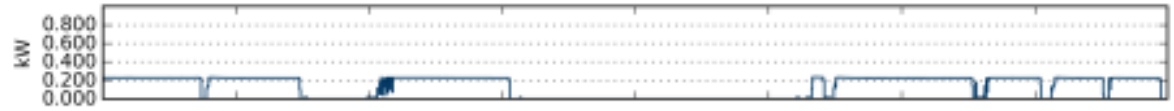

AirHandler

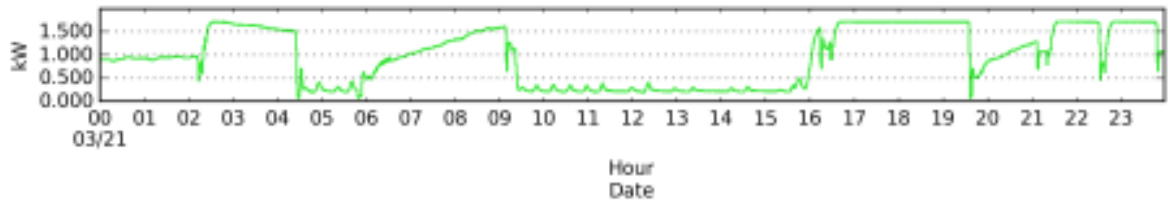

Condenser

Figure 10. Heating high fan speed

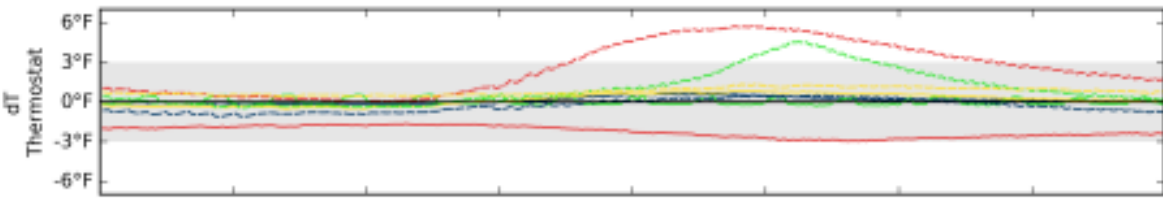

- Dining

- Kitchen

- Finishlasement

Masteriledroom

-- Bedroomz

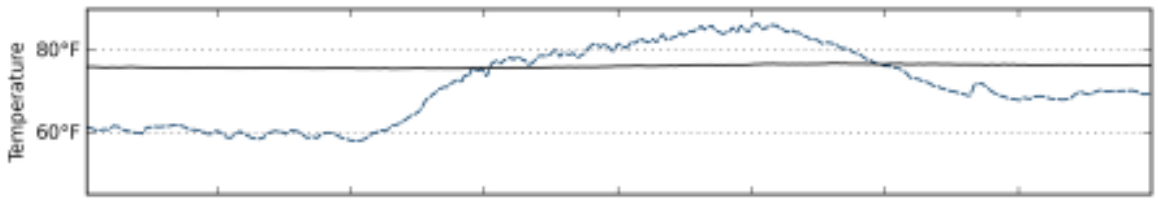

--. Outdoor

- Thermostat

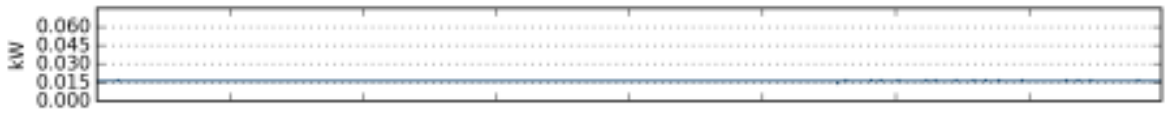

\section{- AirHandler}

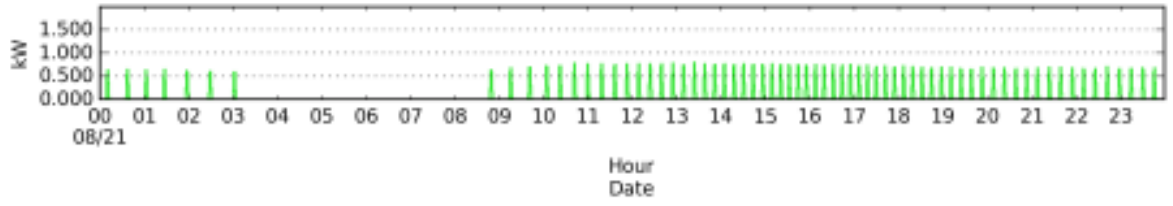

Condenser

Figure 11. Cooling low fan speed 

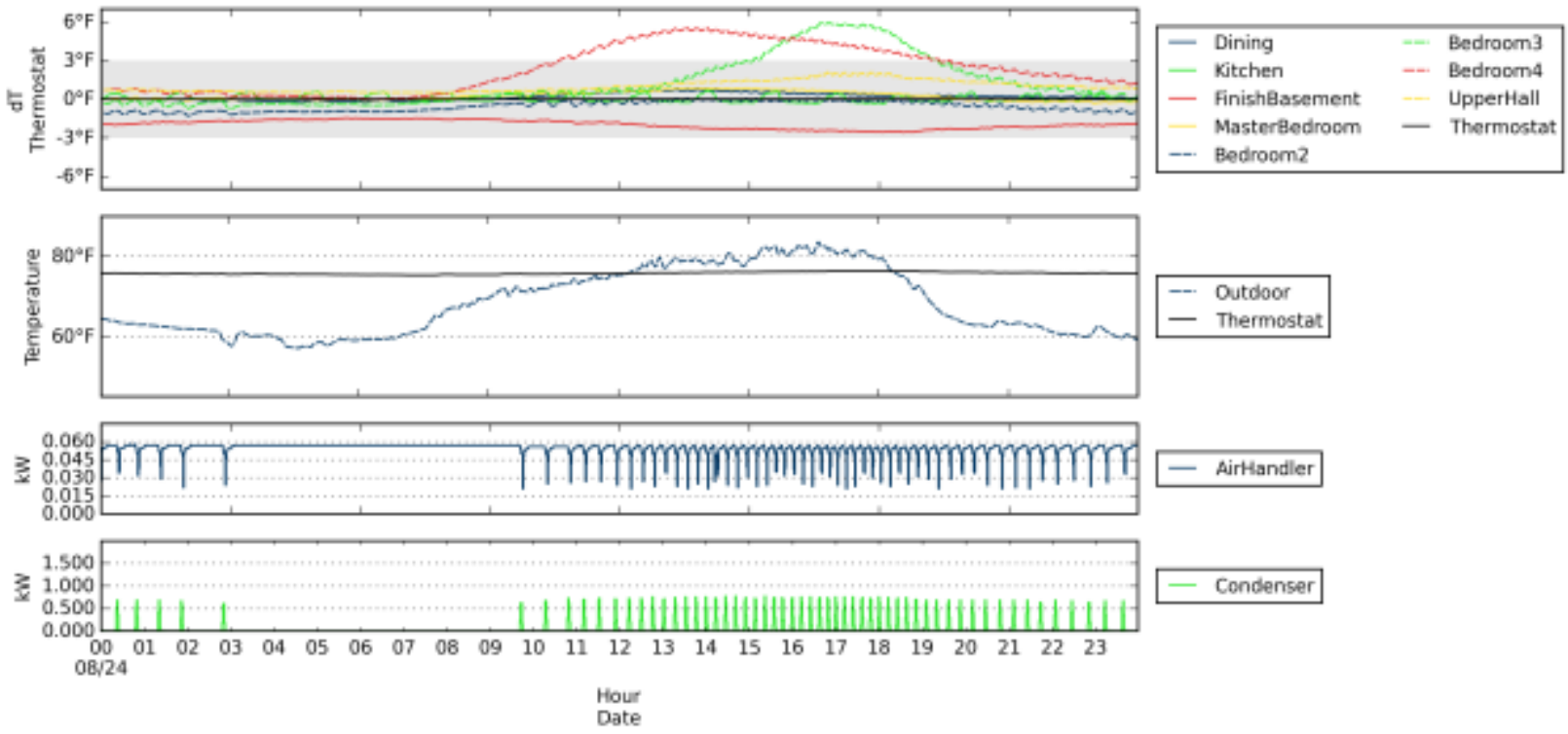

Condenser

Figure 12. Cooling medium fan speed
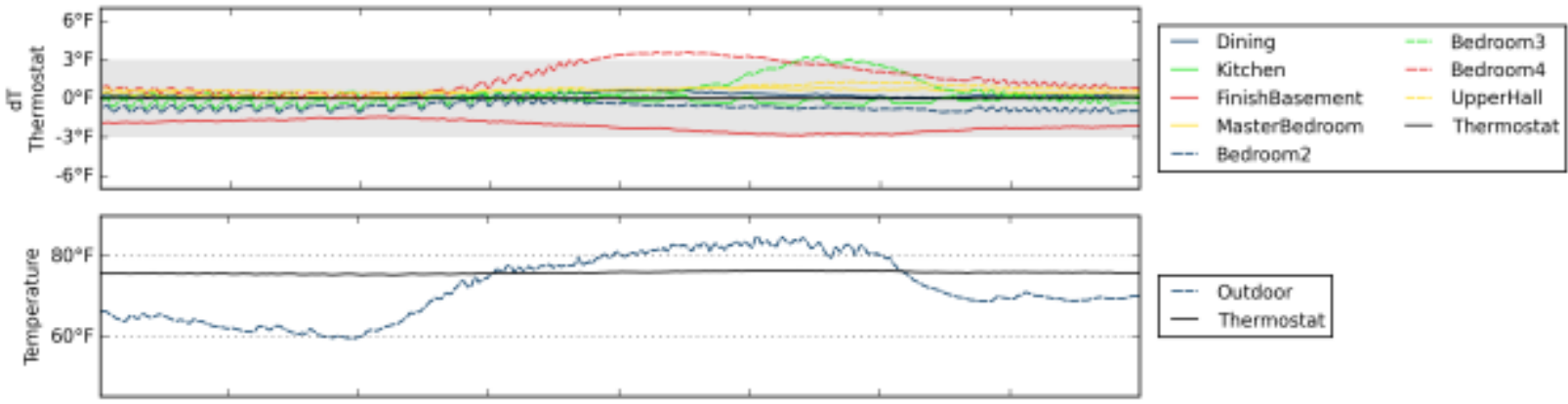

\section{--. Outdoor \\ - Thermostat}

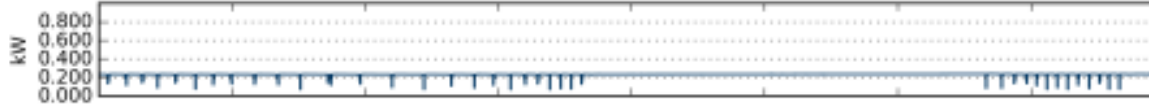

\section{- AirHandler}

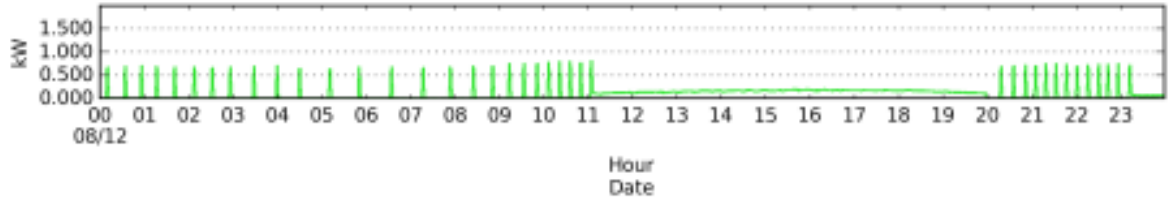

Condenser

Figure 13. Cooling high fan speed

\subsection{Fan Energy Relation to Delivered Energy}

For each flow rate and weather condition type, the total thermal energy delivered to the house and the total fan energy necessary to deliver that thermal energy were summed over the course of the monitoring period. As shown in Table 13 by the delivery ratio - and based on the fan curve for the system as documented by Unico (2011) - the low fan speed mode provided the most thermal energy per unit fan energy as expected. Other factors that influenced the thermal energy delivery ratio include the system runtime and operation frequency. Energy exchange across the heat pump indoor unit was determined by calculating the change in enthalpy of the entering and leaving air and multiplying it by the mass flow rate of air. These calculations were performed only for periods when the system was on. 
Table 13. Energy Performance on Representative Days

\begin{tabular}{|c|c|c|c|c|c|c|c|}
\hline Season & $\begin{array}{l}\text { Mode } \\
\text { (CFM) }\end{array}$ & $\begin{array}{c}\text { Fan Efficacy } \\
(W / \mathrm{cfm})\end{array}$ & $\begin{array}{l}\text { External } \\
\text { Static } \\
\text { Pressure }^{a} \\
\text { (in.) } \\
\end{array}$ & $\begin{array}{c}\text { Outdoor } \\
\text { Temperature } \\
\left({ }^{\circ} \mathbf{F}\right)\end{array}$ & $\begin{array}{c}\text { Total }^{\mathbf{b}} \\
\text { Delivered } \\
\text { Energy } \\
\text { (Btu) } \\
\end{array}$ & $\begin{array}{c}\text { Total Fan } \\
\text { Energy } \\
\text { (Btu) }\end{array}$ & $\begin{array}{c}\text { Delivery } \\
\text { Ratio } \\
\text { (Btu/Btu) }\end{array}$ \\
\hline \multirow{3}{*}{ Heating } & Low (132) & 0.15 & 0.12 & 35.8 & 134,000 & 1,222 & 108.0 \\
\hline & Med. (255) & 0.24 & 0.41 & 45.2 & 137,000 & 4,165 & 33.7 \\
\hline & High (409) & 0.56 & 1.22 & 23.8 & 176,000 & 11,085 & 12.2 \\
\hline \multirow{3}{*}{ Cooling } & Low (121) & 0.17 & 0.12 & 71.5 & 29,700 & 1,311 & 22.7 \\
\hline & Med. (247) & 0.24 & 0.41 & 68.3 & 30,200 & 4,412 & 7.0 \\
\hline & High (427) & 0.53 & 1.22 & 72.1 & 52,400 & 18,848 & 2.8 \\
\hline Heating & Trad. (435) & 0.09 & $-^{\mathrm{c}}$ & 27.3 & $52,000^{\mathrm{d}}$ & 1,785 & 28.9 \\
\hline Cooling & Trad. (435) & 0.09 & $-^{\mathrm{c}}$ & 69.4 & $58,900^{\mathrm{d}}$ & 1,733 & 34.4 \\
\hline
\end{tabular}

${ }^{a}$ Static pressure rise from the return plenum to the supply plenum in in. water column.

${ }^{\mathrm{b}}$ Total thermal energy (sensible and latent) added to or removed from the airstream (return to supply).

${ }^{\mathrm{c}}$ External static pressure was not measured for the traditional duct system.

${ }^{\mathrm{d}}$ For the traditional system test, total delivered energy was higher in cooling mode and lower in heating mode due to simulated internal gains, as discussed in a previous cold-climate unoccupied test house report (Poerschke and Stecher 2014).

The delivery ratio of the small-diameter duct system was difficult to compare to the traditional single-stage compressor system because the thermal output of the heat pump modulated and maintained a constant airflow. 


\section{Discussion}

The results from this study indicate that the high-velocity low-volume system adequately conditions the rooms. The results from individual analyses are detailed in the following discussion.

\subsection{ASHRAE Standard 55-2010 Temperature Variations With Time}

All flow rates successfully avoided failures in cyclic and drift temperature variations $100 \%$ of the time during cooling mode over the summer days analyzed. ASHRAE Standard 55 (ASHRAE 2010a) cyclic and drift failures have to do with the rate of temperature change (temperature change over time) whereas ACCA Manual RS (Rutkowski 1997) room-to-thermostat nonuniformity is not relative to rates of temperature change but to temperature differences. The southern rooms did see some room-to-thermostat temperature nonuniformity that was caused by solar gains even though the rate of temperature rise was low enough to not be picked up as a cyclic or drift failure.

During heating mode solar gains and AHU operational time contributed to cyclic and drift failures in the bedrooms. In the winter, the outdoor unit coil occasionally must be defrosted. The defrost cycle reverses the refrigerant flow and the unit operates in cooling mode during the defrost cycle. Traditional heat pumps typically energize electric resistance heating to offset the cooling effect during the defrost cycle; however, this did not occur with this tested variablecapacity heat pump. This resulted in cyclic and drift failures on typical heating days. This effect was most pronounced with the high-speed fan operation because of the greater cooling effect to the conditioned space during defrost, which happened on cold cloudy days as well as sunny days (see Figure 10). A control strategy that defrosts the outdoor coil only when absolutely neededbased on temperature and not on time alone-would reduce the frequency and duration of these cyclic and drift failures.

\subsection{ACCA Manual RS Room-to-Thermostat Temperature Uniformity}

The ACCA Manual RS (Rutkowski 1997) room-to-thermostat spatial uniformity analysis revealed a variety of potential comfort risks that were not flagged by the ASHRAE Standard 55 analysis (ASHRAE 2010a) of cyclic and drift temperature variation with time. A temperature nonuniformity failure was deemed to occur when the room-to-thermostat temperature difference exceeded $2^{\circ} \mathrm{F}$.

In heating mode, the basement and master bedroom had a $100 \%$ incidence of temperature uniformity failure at all fan speeds because of insufficient airflow. Increasing the airflow to the basement zone may cause overcooling in the summer. In a case such as this, the HVAC system designer should decide which season should maintain a temperature closer to the set point. Alternatively, an adjustable damper should be installed. The master bedroom received only $64 \%$ of its design airflow. This bedroom was at the end of the longest duct run and was consistently $3^{\circ}-5^{\circ} \mathrm{F}$ lower than the thermostat reading. This temperature nonuniformity failure could be fixed by installing another duct run or by installing a larger-diameter duct to increase the airflow to this room. The heating and cooling airflow requirements for the master bedroom were nearly the same (36 cfm heating versus $37 \mathrm{cfm}$ cooling); therefore, adding airflow to that zone would not cause overcooling in the summer. Bedroom 3 had a high incidence of temperature nonuniformity at high fan speed. This south-facing bedroom exhibited several periods of underheating overnight 
because of the large glazing-to-wall area ratio and insufficient airflow to meet that load. It also showed overheating on sunny days in heating mode. Bedroom 4 had a high incidence of temperature nonuniformity at low fan speed because of insufficient (below-design) airflow but showed overheating on sunny days in heating mode.

In cooling mode, west-facing bedroom 3 had a high incidence of temperature nonuniformity at both medium-speed (design) and low-speed airflow. South-facing bedroom 4 showed high roomto-thermostat nonuniformity at all airflow levels. Both bedrooms had below-design cooling airflow but above-design heating airflow. The overheating was due to insufficient cooling mode airflow and solar gains (see Figure 11 through Figure 13). During typical sunny days in cooling mode these south-facing and west-facing bedrooms overheated by more than $3^{\circ} \mathrm{F} 3 \%-40 \%$ of the time because of solar heat gains. Running the system at a higher fan speed reduced the percentage of overheating time from $40 \%$ to $18 \%$ in one case on similar sunny summer days. Also shown in Figure 11 through Figure 13 is the effect of the refrigerator cycling on the kitchen temperature. Periodic temperature spikes are apparent with quick returns to the set point.

The change in fan speed between different modes of operation did not fundamentally mitigate the temperature nonuniformities. In heating mode, the increased fan speed exacerbated airflow imbalances to each room. In cooling mode, increased airflow improved uniformity and reduced the failure rates of bedroom 3 and bedroom 4 from $13 \%$ to $3 \%$ and $40 \%$ to $18 \%$, respectively.

\subsection{Fan Energy Relation to Delivered Energy}

The amount of fan energy needed to deliver the conditioned air is a function of several factors: efficiency of the fan and motor, the static pressure restriction of the duct system, and the temperature change across the coil.

Differences in testing procedures between the small-diameter duct system and the traditional centrally ducted system meant that a direct comparison of delivery efficiency was impossible. However, the small-diameter system could likely provide a similar delivery efficiency as the traditional system when operating at the medium (design) fan speed in heating and the low fan speed in cooling. Total delivered energy was lower in cooling mode because the heat pump compressor operated at a higher speed and capacity during the heating tests, which resulted in more heat exchange across the indoor coil. (Refer to the condenser plots in Figure 8 through Figure 13.)

Throughout the period presented in Table 13, the traditional centrally ducted system operated in a single stage and at a single fan speed while the small-diameter system had almost continuous fan operation (as shown in Figure 8 through Figure 13). The small-diameter duct system operated with a total external static pressure that ranged from 0.12 to $1.22 \mathrm{in}$. water column compared to published values of 0.41 to 0.50 that can be expected for traditional duct systems. Measured fan efficacy was $0.15-0.56 / \mathrm{W} / \mathrm{ft}^{3} / \mathrm{min}$ of airflow for the small-diameter duct system. At the medium and high speeds and running the indoor fan almost continuously while the heat pump thermal output modulated, the small-diameter duct system used more fan energy than the traditional duct system. Both medium and high fan speeds were needed at times to meet the temperature set point and to achieve temperature uniformity. A control strategy that runs the fan at the lowest speed to meet most load hours and switches to higher speeds only under peak load conditions would offer the best trade-off between comfort and fan energy. 


\section{Cost Analysis}

The U.S. Department of Energy Building Technologies Program concluded that significant energy savings are associated with bringing ductwork inside conditioned space (DOE 2013). This measure minimizes duct losses, which allows system capacity to be reduced. The lack of floor structure available for routing ducts in the single-story slab-on-grade construction type that is prevalent in the South and Southeast presents the biggest challenge in bringing ducts inside the conditioned space.

Two means of moving the ductwork into conditioned space were evaluated in DOE (2013): (1) create a conditioned attic by insulating against the underside of the roof sheathing or (2) create bulkheads or lowered/dropped ceilings beneath the bottom chord of the roof truss through which the ductwork is run. For the second method, the smaller ductwork would reduce the depth of the bulkheads, could potentially be more architecturally acceptable, and would reduce installation costs somewhat. This analysis showed an increase in heat pump equipment cost for the high-velocity small-diameter duct system and acknowledged reductions in the cost of additional framing for bulkheads.

Fonorow et al. (2010) used actual construction cost data from a builder in Florida to assess the cost implications of moving a traditional duct system into conditioned space through a bulkhead scenario. That study found that bulkheads could be built to architecturally enhance the builder's particular floor plan and that it would cost less to build a bulkhead versus insulating the roof deck to create a conditioned attic. However, the study was limited to traditional-size ductwork and did not discuss the use of small-diameter ducts. Although not estimated in this study, smalldiameter ducts (i.e., diameters of 2 to $2-1 / 2$ in.) would allow for installation within $2 \times 4$ interior wall cavities and may reduce the number of bulkheads.

\subsection{Methods}

To determine if the use of small-diameter ductwork has significant installation cost advantages, the team performed a cost comparison by examining small-diameter and traditional duct layouts for a common slab-on-grade floor plan from a builder in Dallas, Texas. IBACOS chose this style of construction and corresponding climate because ductwork and HVAC equipment in such homes typically are installed in unconditioned attics. Conditioned attic scenarios had already been shown to be more expensive and would not offer any additional savings with the smalldiameter duct system because they have plenty of space to route traditional ductwork. This cost analysis was performed by comparing the total installed cost-labor and materials for the HVAC system, ductwork, and relevant framing, insulation, and finish materials - of a small-diameter duct system to the total cost of a standard-diameter system installed in conditioned space using a bulkhead and dropped ceiling scenario.

\subsubsection{Uncertainty Analysis}

The comparison can give only a general range of the cost differences because multiple sources were required for cost data. Therefore, the costs should be considered as very loose estimates only for discussion purposes and with high uncertainty.

Construction cost analysis for the HVAC system was performed using RSMeans (2012) residential cost values, with the following exceptions: 
- When conducting a cost analysis of the standard-diameter ductwork and equipment, the National Residential Efficiency Measures Database ${ }^{9}$ was used for equipment (AHU and outdoor unit) costs because RSMeans did not break out separate costs based on equipment performance.

- To analyze the small-diameter duct system, cost data obtained from the manufacturer were used for the study because neither RSMeans nor the National Residential Efficiency Measures Database have costs for this system.

\subsubsection{House Type}

The floor plan selected was a single-story house of approximately $2,000 \mathrm{ft}^{2}$ that separated the master suite from the other bedrooms. Figure 14 shows the floor plan with the small-diameter duct layout and bulkhead locations. ACCA Manual J heating and cooling loads representative of the low-load construction type are $31,000 \mathrm{Btu} / \mathrm{h}$ and $26,000 \mathrm{Btu} / \mathrm{h}$, respectively (Rutkowski 2006).

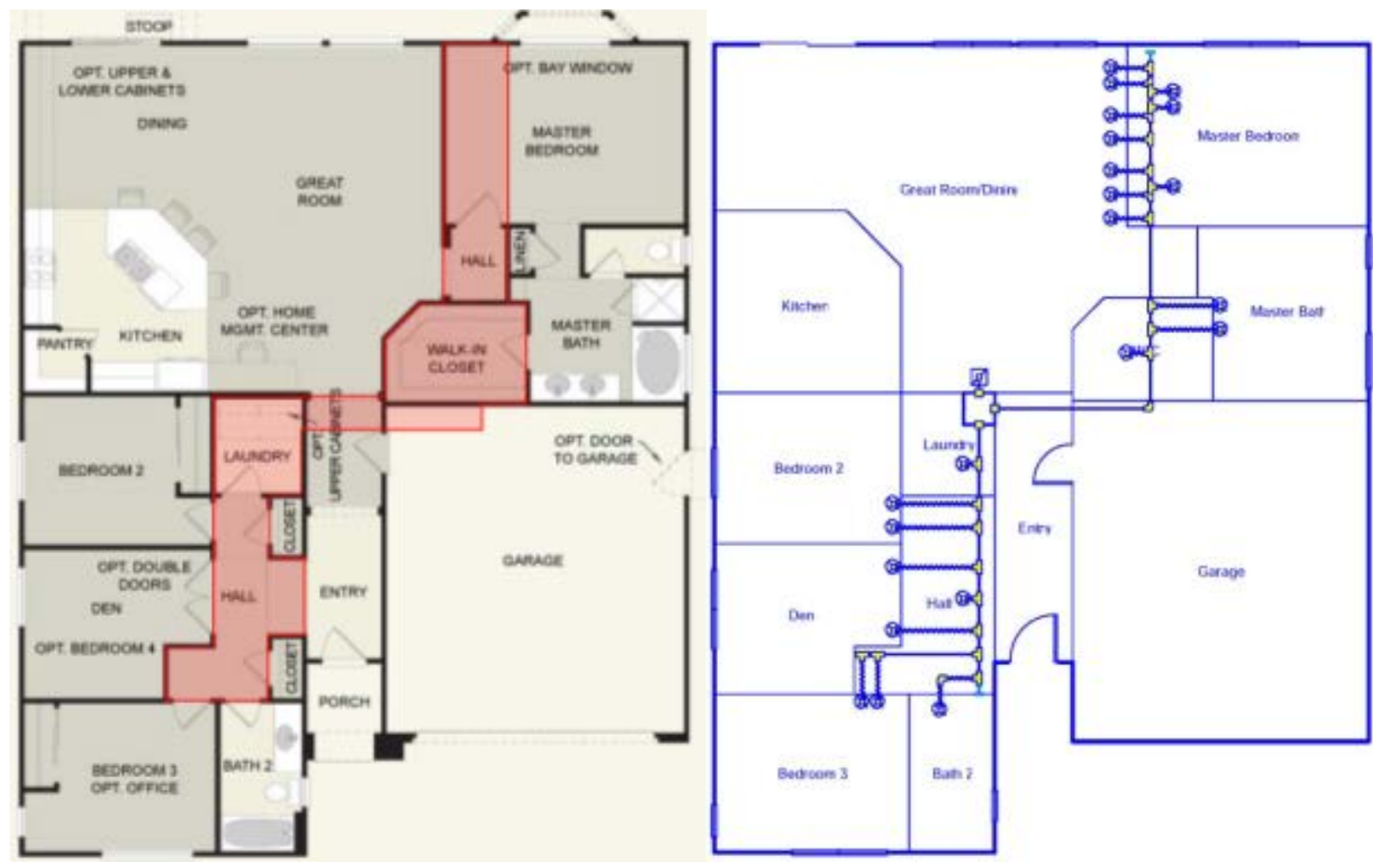

Figure 14. Bulkhead (dropped ceiling) location and duct layout for small-diameter ducts

\subsection{Results of Cost Comparison}

A cost advantage was estimated for the small-diameter duct system as shown in Table 14. For the small-diameter duct system, the bulkhead construction cost $\$ 100$ less than for a traditional-size duct system. The duct material and AHU combined cost $\$ 2,100$ less and the outdoor heat pump unit cost $\$ 1,700$ more, yielding a predicted net savings of $\$ 500$. These estimates for small-

\footnotetext{
${ }^{9}$ National Residential Efficiency Measures Database. Golden, CO: National Renewable Energy Laboratory. http://www.nrel.gov/ap/retrofits/.
} 
diameter high velocity systems compared to traditional systems are only for discussion purposes and the uncertainty discussed in Section 5.1.1 must be considered.

Table 14. Cost Comparison Summary*

\begin{tabular}{l|l|l|l|l}
\hline $\begin{array}{l}\text { Duct } \\
\text { System }\end{array}$ & $\begin{array}{l}\text { Bulkhead } \\
\text { Construction }\end{array}$ & $\begin{array}{l}\text { Ductwork } \\
\text { and AHU }\end{array}$ & $\begin{array}{l}\text { Outdoor } \\
\text { HP Unit }\end{array}$ & $\begin{array}{l}\text { Total } \\
\text { Cost }\end{array}$ \\
\hline Traditional & $\$ 1,200$ & $\$ 7,400$ & $\$ 700$ & $\$ 9,300$ \\
Small & $\$ 1,100$ & $\$ 5,300$ & $\$ 2,400$ & $\$ 8,800$ \\
\hline
\end{tabular}

* All costs are rounded to the nearest $\$ 100$ and are based on various sources. 


\section{Conclusions}

Building on the results of previous studies conducted in the Pittsburgh, Pennsylvania, newconstruction unoccupied test house and in other test houses, IBACOS tested and evaluated the performance of a varied airflow small-diameter duct system in regard to occupant comfort and energy consumption in a low-load house. A cost analysis showed that installing the smalldiameter duct system inside conditioned space was less expensive than accomplishing the same thing with traditionally sized ducts. However, this work also has shown that duct configuration and zone temperature control issues remain. These need to be resolved before small-diameter duct systems can reliably provide room-to-thermostat temperature uniformity throughout lowload homes.

The research questions for this project are answered here.

1. In a low-load home (normalized heating and cooling loads lower than $10 \mathrm{Btu} / \mathrm{h}-\mathrm{ft}^{2}$ of floor area) with ducts in conditioned space, what is the impact of operating a smalldiameter duct system (2-in. diameter) at three different but constant flow rates connected to a variable-capacity heat pump, on temperature variation with time based on ASHRAE Standard 55-2010 (ASHRAE 2010a), on room-to-thermostat uniformity as specified by ACCA Manual RS (Rutkowski 1997), system runtime, and fan efficacy?

Three airflow scenarios were evaluated for their ability to meet the ASHRAE Standard 55 (ASHRAE 2010a) limits for temperature variation with time and the ACCA Manual RS (Rutkowski 1997) guidelines for spatial temperature uniformity. During the cooling season, measured data showed that all three tested constant airflow scenarios had no ASHRAE cyclic or drift temperature variation failures. Heating season data showed cyclic and drift failures when the space was being cooled during defrost cycles without auxiliary heat energized. These heating season failures were most pronounced in the high airflow scenario when cooling capacity was highest. Using ACCA guidelines for room-to-thermostat temperature uniformity (Rutkowski 1997), analysis of the small-diameter duct system performance data showed that some rooms were consistently too hot or too cold because of too little or too much airflow or solar gains. This highlighted the need for improved systems with a more effective airflow control strategy in lowload homes.

Solar gains strongly influenced the success of the small-diameter duct system in maintaining room-to-thermostat temperature uniformity for the south-facing and west-facing bedrooms. These rooms represented the worst-case scenario because they had complete southern or western exposure with no shading. With the small-diameter duct system running in the lowest airflow cooling mode $(132 \mathrm{cfm})$, the south-facing bedroom overheated $13 \%$ of the time; the west-facing bedroom overheated $40 \%$ of the time on a sunny day. Increasing the airflow of the smalldiameter duct system to $435 \mathrm{cfm}$ reduced those failure rates to $3 \%$ and $18 \%$, respectively. These results suggest that the small-diameter duct system can operate most of the time using a lower flow rate and increase the flow rate only for peak solar conditions.

Measured fan efficacy was $0.15-0.56 \mathrm{~W} / \mathrm{ft}^{3} / \mathrm{min}$ of airflow for the small-diameter duct system. At medium and high speeds and when running the indoor fan almost continuously while the heat pump thermal output modulated, the small-diameter duct system used more fan energy than the 
traditional duct system. Both medium and high fan speeds were needed at times to meet the temperature set point and to achieve temperature uniformity. A control strategy that runs the fan at the lowest speed to meet most load hours while switching to higher speeds only during peak load conditions would offer the best trade-off between comfort and fan energy.

2. What is the range of external static pressure required to deliver conditioned air through a small-diameter duct system. How does it compare to that of an HVAC system with traditional duct sizes?

The small-diameter duct system operated with a total external static pressure that ranged from 0.12 to $1.22 \mathrm{in}$. water column compared to published values of 0.41 to 0.50 that can be expected for traditional duct systems. The measured external static pressure of the small-diameter duct system at the medium fan speed (standard design condition) was 0.41 in. water column, which was at the low end of traditional duct systems.

3. What is the cost implication of installing small-diameter ducts in conditioned space compared to traditional duct sizes?

A cost advantage was estimated for installing the small-diameter duct system inside conditioned space compared to doing the same with traditionally sized ducts. For the small-diameter duct system the bulkhead construction cost $\$ 100$ less and the duct material and AHU combined cost $\$ 2,100$ less; however, the outdoor heat pump unit cost $\$ 1,700$ more and yielded a predicted net savings of $\$ 500$. These estimates for small-diameter high velocity systems as compared to traditional systems are for discussion purposes only and have a relatively high uncertainty. 


\section{Future Work}

Learning from the monitored data in the Pittsburgh, Pennsylvania, new-construction unoccupied test house, the research team plans to continue research on small-diameter duct systems from several approaches.

During the analysis phase of the project, the team compared measured data to values predicted by a detailed whole-house TRNSYS model. The team determined several parameters were most significant in achieving an accurate model. These parameters include the volumetric airflow out of each diffuser and the room-to-room coupling airflow between system operations. Because airflow is the largest source of uncertainty in this project, future modeling efforts should use a detailed airflow model such as CONTAM to achieve accurate results. Future work can use the lessons learned from this exercise to model the impact of the small-diameter duct system in different climate zones and use different control strategies.

In addition to simulating the small-diameter duct system in different climate zones, future work should look at strategies to provide a better method of balancing each duct run. Design strategies that can position the AHU centrally within the house floor plan can reduce the length of duct runs, which would further reduce cost and fan energy consumption compared to systems with the same duct sizes. The central position of the AHU can shorten the distance to the longest duct runs and improve airflow. Long duct runs for a few of the rooms in the test house presented airflow balancing problems in this study. 


\section{References}

Aldrich, R. (2009). "Efficient Houses with Minimal HVAC." Presented at the Northeast Sustainable Energy Association's Building Energy 2011 Conference, Boston, MA, March 2011.

ASHRAE (2010a). ANSI/ASHRAE Standard 55-2010, Thermal Environmental Conditions for Human Occupancy. Atlanta, GA: ASHRAE.

ASHRAE (2010b). ANSI/ASHRAE Standard 62.2 - 2010. Ventilation and Acceptable Indoor Air Quality in Low-Rise Residential Buildings. Atlanta, GA: ASHRAE.

BEopt (2012). BEopt. Building Energy Optimization with Hour-by-Hour Simulations, Version 1.2. Golden, CO: National Renewable Energy Laboratory.

Broniek, J. (2008). "Could a European Super Energy Efficient Standard Be Suitable for the U.S.?" Presented at the BEST1 Conference, Minneapolis, MN, June 2008. Accessed April 17, 2015: http://c.ymcdn.com/sites/www.nibs.org/resource/resmgr/BEST/BEST1_041.pdf.

DOE (2013). “Ducts in Conditioned Space.” U.S. Department of Energy Building Technologies Program. Accessed April 17, 2015:

http://apps1.eere.energy.gov/buildings/publications/pdfs/building_america/1 $1 \mathrm{~g}$ ba innov_ducts conditionedspace 011713.pdf.

Fonorow, K.; Jenkins, D.; Thomas-Rees, S.; Chandra, S. (2010). "Low Cost Interior Duct Systems for High Performance Homes in Hot Climates." ACEEE Summer Study on Energy Efficiency in Buildings, Pacific Grove, CA, August 15-20, 2010. Cocoa, FL: Florida Solar Energy Center.

Hendron, R.; Engebrecht, C. (2010). Building America Research Benchmark Definition, Updated December 2009. Golden, CO: National Renewable Energy Laboratory, NREL/TP-550-47246. Accessed July 5, 2012: http:/www.nrel.gov/docs/fy10osti/47246.pdf.

IBACOS (2006a). "Evaluation of Advanced Systems Research Plan.” Pittsburgh, PA: IBACOS KAAX-3-33410-11.A.2 (unpublished).

IBACOS (2006b). "Evaluation of Advanced Systems Research Plan." Pittsburgh, PA: IBACOS KAAX-3-33410-11.B.1 (unpublished).

IBACOS (2007). "Evaluation of Advanced Systems Research Plan.” Pittsburgh, PA: IBACOS KAAX-3-33410-14.B.1 (unpublished).

IECC (2012). 2012 International Energy Conservation Code. Washington, DC: International Code Council.

Oberg, B. (2010). Cooperative Agreement DE-FC26-08NT02231. Building America Final Technical Report. Pittsburgh, PA: IBACOS (unpublished). 
Poerschke, A.; Stecher, D. (2014). Simplified Space Conditioning in Low-Load Homes: Results from Pittsburgh, Pennsylvania, New Construction Unoccupied Test House. Golden, CO: National Renewable Energy Laboratory, NREL/SR-5500-62122.

Proctor, J.; Parker, D. (2000). "Hidden Power Drains: Residential Heating and Cooling Fan Power Demand." Proceedings of the 2000 Summer Study on Energy Efficiency in Buildings, Vo1. 1. Washington, DC: American Council for an Energy-Efficient Economy. Accessed April 17, 2015: http://aceee.org/files/proceedings/2000/data/papers/SS00_Panel1_Paper19.pdf.

Rittelmann, W.D. (2008). “Thermal Comfort Performance: Field Investigation of a Residential Forced-Air Heating and Cooling System with High Sidewall Supply Air Outlets." Building Enclosure Science and Technology Conference, June 10-12, 2008. Accessed April 17, 2015: http://c.ymcdn.com/sites/www.nibs.org/resource/resmgr/BEST/BEST1 045.pdf.

RSMeans (2012). RSMeans Residential Cost Data 2012. Robert S. Means Co.; 31st ed., October 31, 2011.

Rutkowski, H. (1995). Manual S-Residential Equipment Selection. Arlington, VA: Air Conditioning Contractors of America.

Rutkowski, H. (1997). Manual RS-Comfort, Air Quality, and Efficiency by Design, 1 st ed. Washington, DC: Air Conditioning Contractors of America Educational Institute.

Rutkowski, H. (2006). Manual J-Residential Load Calculation, 8th ed., Version 2. Arlington, VA: Air Conditioning Contractors of America.

Rutkowski, H. (2009b). Manual T-Air Distribution Basics for Residential and Small Commercial Buildings. Arlington, VA: Air Conditioning Contractors of America.

Stecher, D.; Poerschke, A. (2013). Simplified Space Conditioning in Low-Load Homes: Results from Fresno, California, Retrofit Unoccupied Test House. Golden, CO: National Renewable Energy Laboratory, NREL/SR-5500-60712. Accessed April 17, 2015:

http://www.nrel.gov/docs/fy14osti/60712.pdf.

Straub, H.E. (1956). Distribution of Air Within a Room for Year-Round Air Conditioning, Part 1. Champaign, IL: University of Illinois at Urbana Champaign, College of Engineering. Engineering Experiment Station. Accessed October 5, 2012: http://www.ideals.illinois.edu/handle/2142/4438.

TRNSYS (2012). Transient System Simulation Tool. Madison, WI: Thermal Energy System Specialists. Accessed April 17, 2015: http://www.trnsys.com/.

Unico (2011). Unico Bulletin 20-18, M1218 Air Handler. St. Louis, MO: Unico, Inc. March 2011 .

Wrightsoft. (2010). Right-Suite Universal, Version 8.0.20. Lexington, MA: Wrightsoft Corporation. 


\section{Appendix: Instrument and Test HVAC System Commissioning}

\section{Infrared Flow Visualization}

The researchers conducted flow visualization testing using an IR thermal imaging camera in bedroom 3 of the Pittsburgh, Pennsylvania, unoccupied test house. The purpose of this testing was to observe the "throw" and mixing performance of the register at the three flow rates.

\section{Methods}

IR cameras "see" the temperatures of surfaces but not of air. For the camera to see the flow pattern of the air, the research team created a "screen" from a 6-ft by 9-ft black sheet of felt that was mounted on two paint-roller extension poles, a shower rod, and sufficient clamps to hold the assembly together. When this black felt "screen" was placed parallel to the primary flow path from the register, its surface temperature responded based on the temperature and flow pattern of the air leaving the supply register. Then IR pictures of the felt were taken to visually observe flow patterns. The test equipment consisted of an IR camera and the black felt screen assembly as shown in Figure 15.

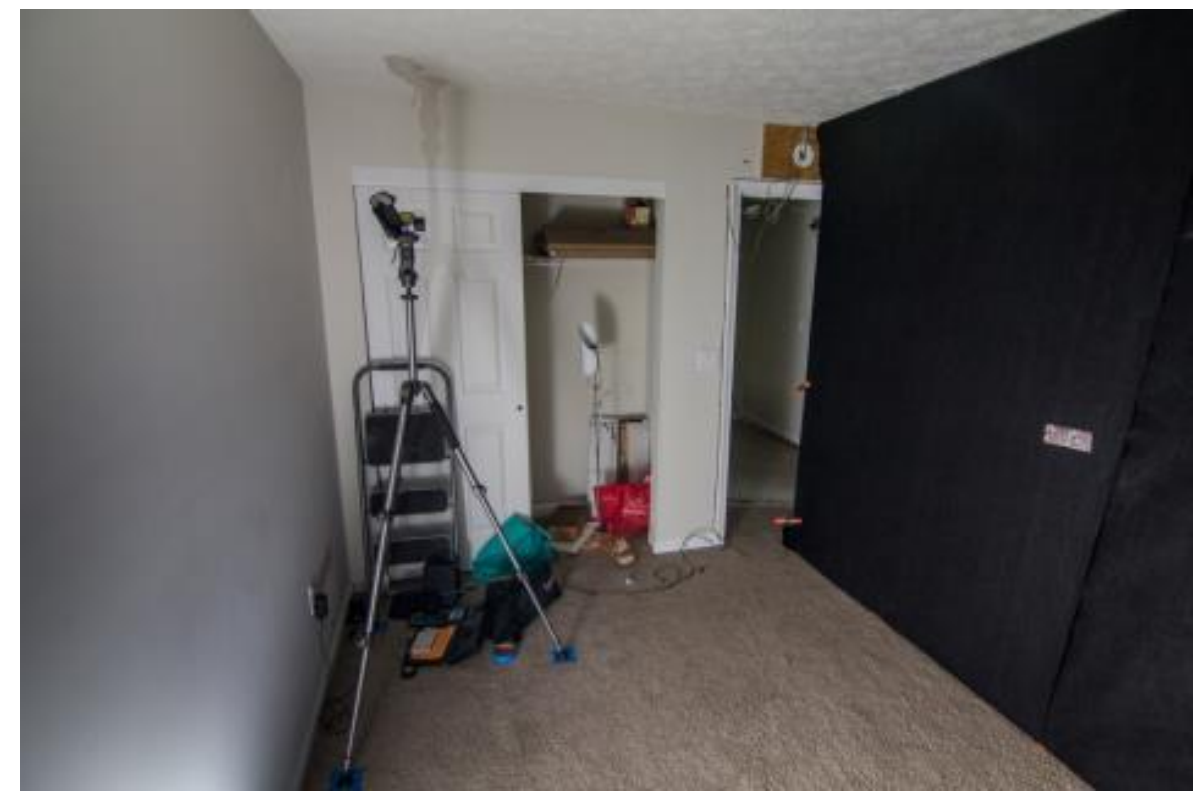

Figure 15. Wide-angle IR camera (left) facing black felt IR viewing screen positioned adjacent to a wall and parallel to the primary register airflow path

The researchers observed flow in both the heating and cooling modes. Six tests were conducted - one at each flow rate in each mode. For each mode, during each test the camera was set to a fixed scale; the maximum value and minimum value were determined before the first test began. In heating mode, the maximum value was $117^{\circ} \mathrm{F}$, which was the heretofore observed maximum supply air temperature value; the minimum value was no less than the ambient room air temperature. In cooling mode, the maximum value was no greater than the ambient room air temperature and the minimum value was $43^{\circ} \mathrm{F}$, which was the heretofore observed minimum supply air temperature value. 
Although a wide-angle lens was used, the researchers still had to position the camera in two locations to capture the entire width of the felt screen. To accomplish this, during the first 10 minutes of system operation photographs were taken every minute from the camera position that could see the end of the felt screen closest to the register. After steady-state flow conditions were observed, the camera was moved to the position where it could see the far end of the felt. The photographs then were stitched together.

Between tests, a box fan was placed in the room and was operated to ensure that the room air was well mixed at the beginning of the next test. The outdoor temperature during testing ranged from $71^{\circ} \mathrm{F}$ to $78^{\circ} \mathrm{F}$; no incident solar radiation occurred through the west-facing window during the time of day when the testing occurred. Additionally, the window was covered with dark shading material and the interior lights were turned off during the testing.

The IBACOS team visually analyzed the photo results to determine the temperature distribution of air in the room during system operation and noted significant stratification or horizontal nonuniformity.

\section{Results}

Outdoor conditions during the test were partly cloudy with $71^{\circ}-78^{\circ} \mathrm{F}$ outdoor temperature and $71^{\circ} \mathrm{F}$ indoor temperature; the testing was performed between 8 a.m. and 1 p.m. Because the outdoor conditions were mild, the researchers could operate the HVAC system in both the heating mode and the cooling mode. During the cooling mode, the observed flow behavior from the register indicated that air was leaving the register, traveling across the upper portion of the room, and beginning to mix as it neared the exterior wall (see Figure 16 through Figure 18). IR images for each of the three flow rates measured during cooling mode were normalized to the room air temperature as measured on the surface of the felt. The images are shown in those figures.

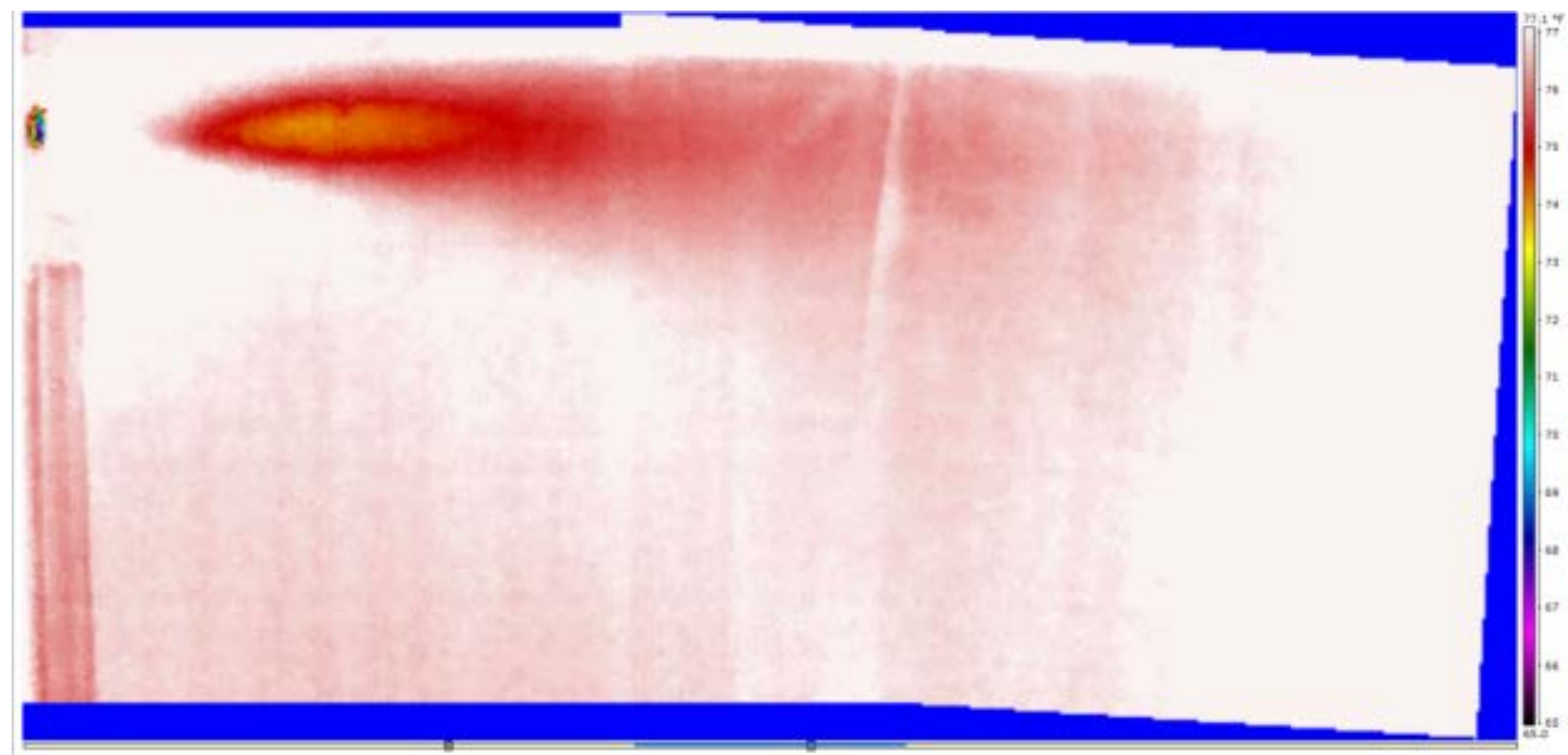

Figure 16. IR photo of the black felt screen during low-speed cooling system operation (temperature scale in ${ }^{\circ} \mathrm{F}$ ) 


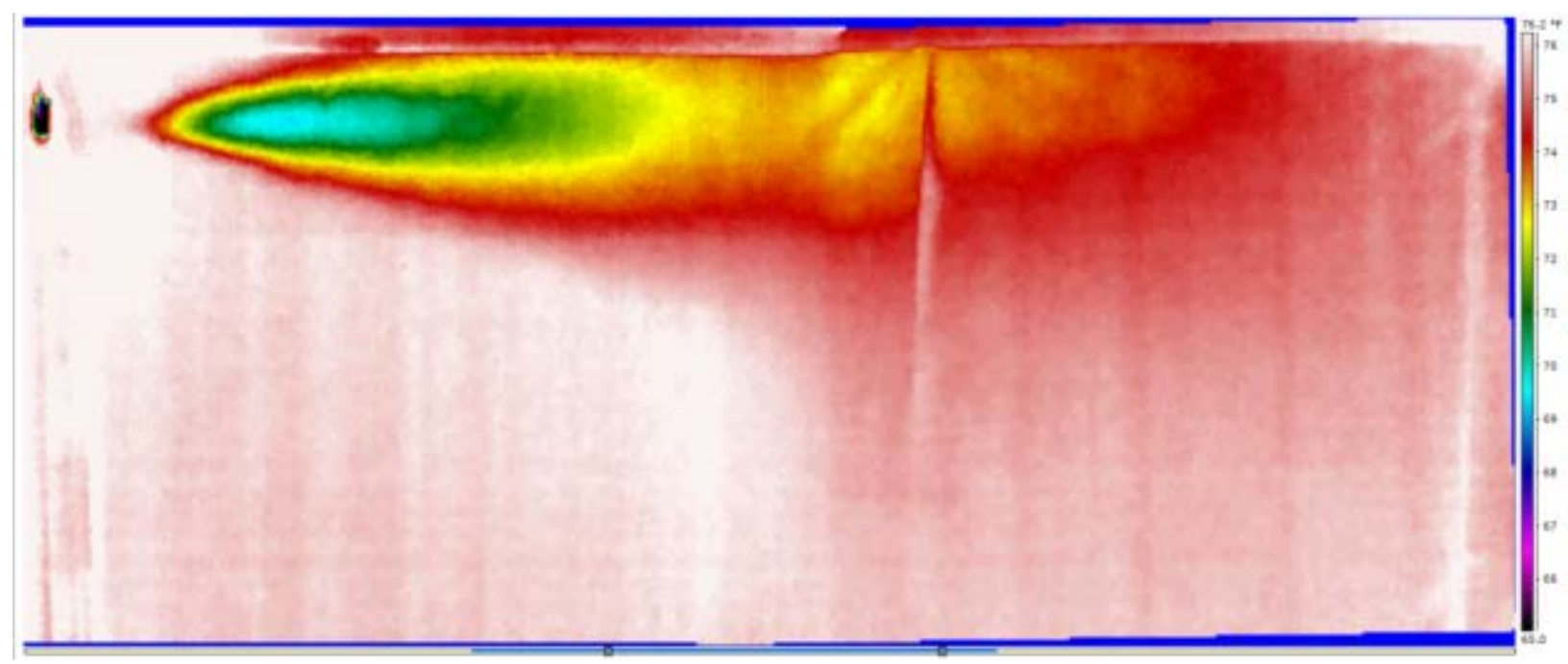

Figure 17. IR photo of the black felt screen during medium-speed cooling system operation (temperature scale in ${ }^{\circ} \mathrm{F}$ )

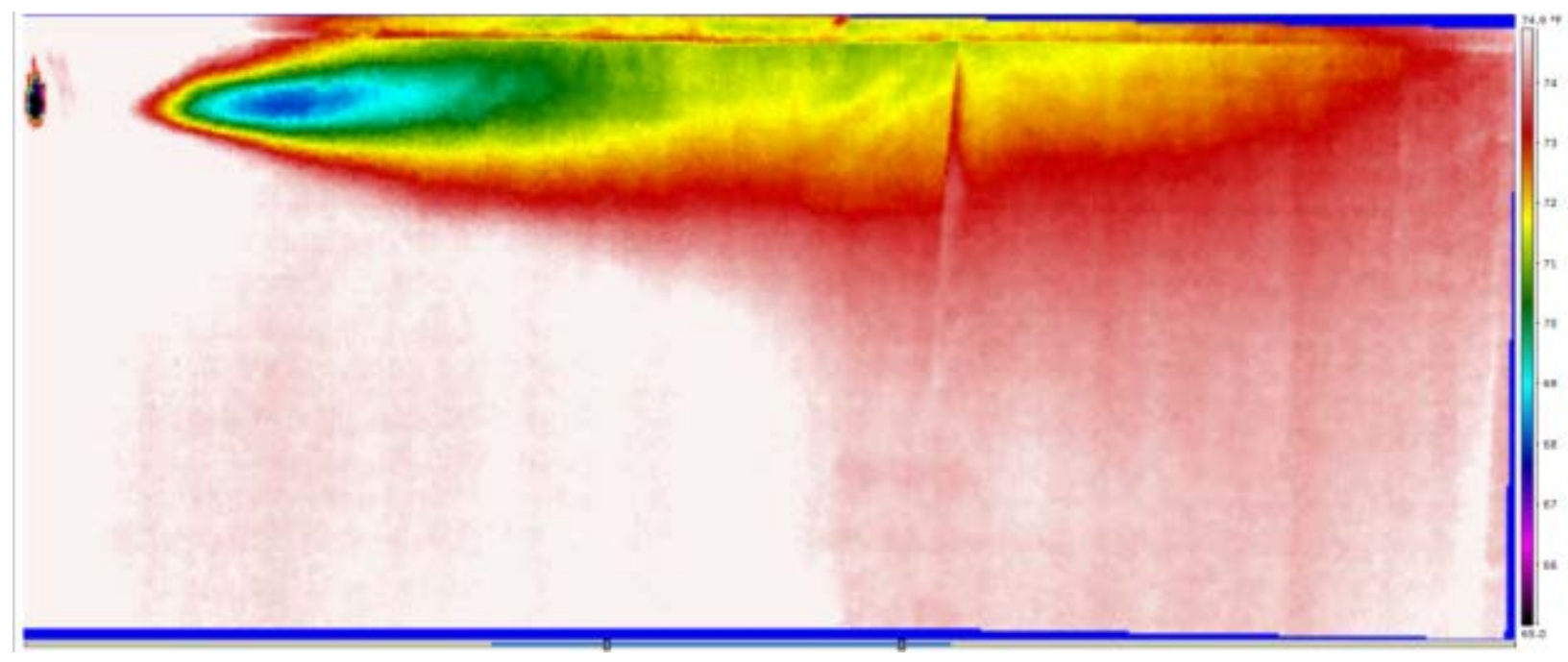

Figure 18. IR photo of the black felt screen during high-speed cooling system operation (temperature scale in ${ }^{\circ} \mathrm{F}$ )

During the heating mode, the observed flow behavior from the register indicated that air was leaving the register, traveling across the upper portion of the room, and beginning to mix as it neared the exterior wall (see Figure 19 through Figure 21). IR images for each of the three flow rates measured during heating mode were normalized to the room air temperature as measured on the surface of the felt. 


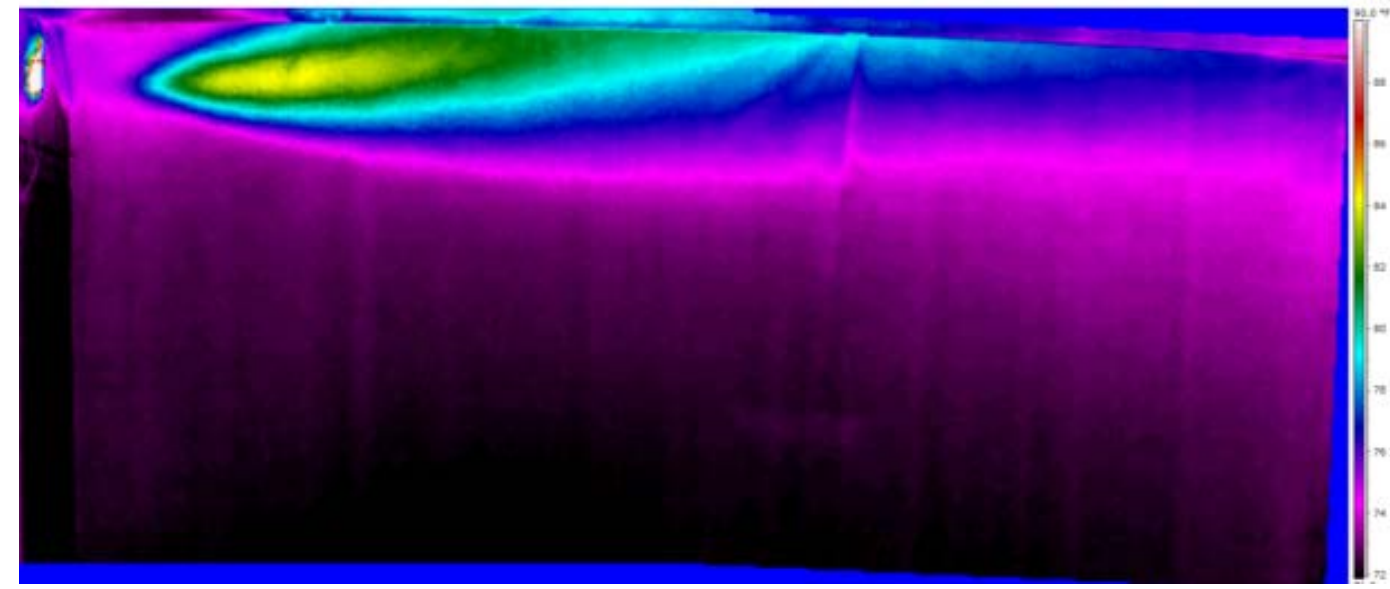

Figure 19. IR photo of the black felt screen during low-speed heating system operation (temperature scale in ${ }^{\circ} \mathrm{F}$ )

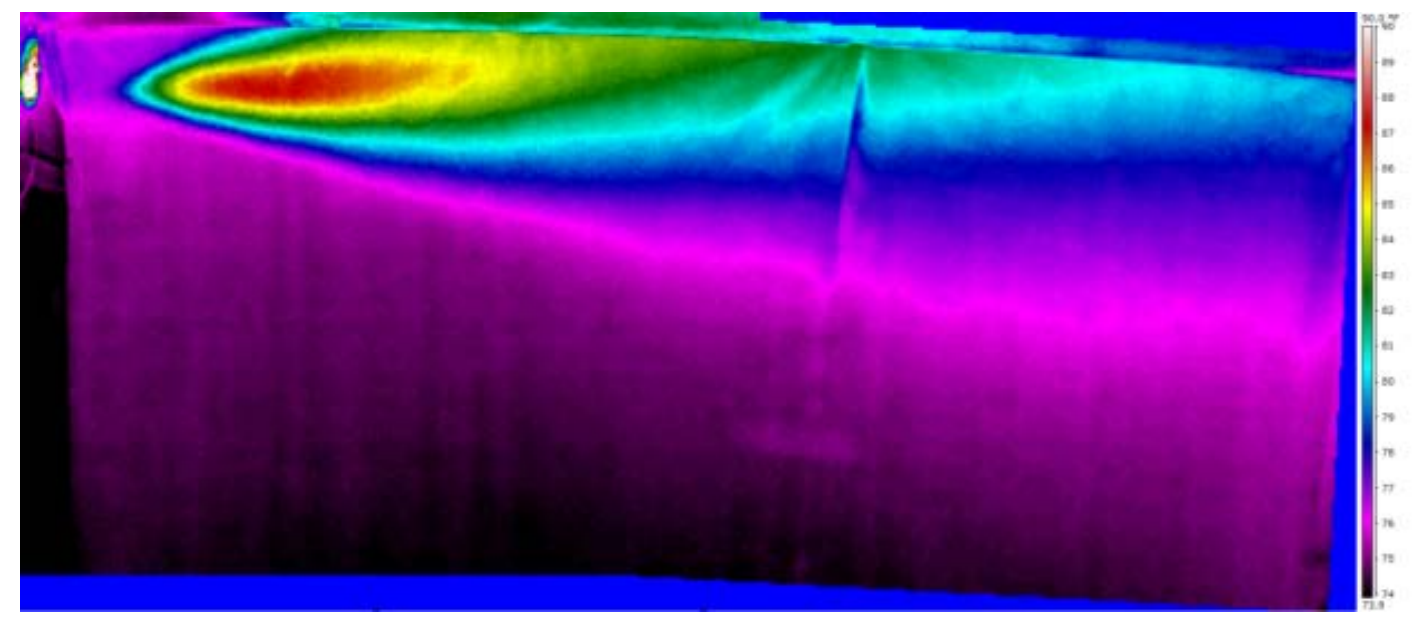

Figure 20. IR photo of the black felt screen during medium-speed heating system operation (temperature scale in ${ }^{\circ} \mathrm{F}$ )

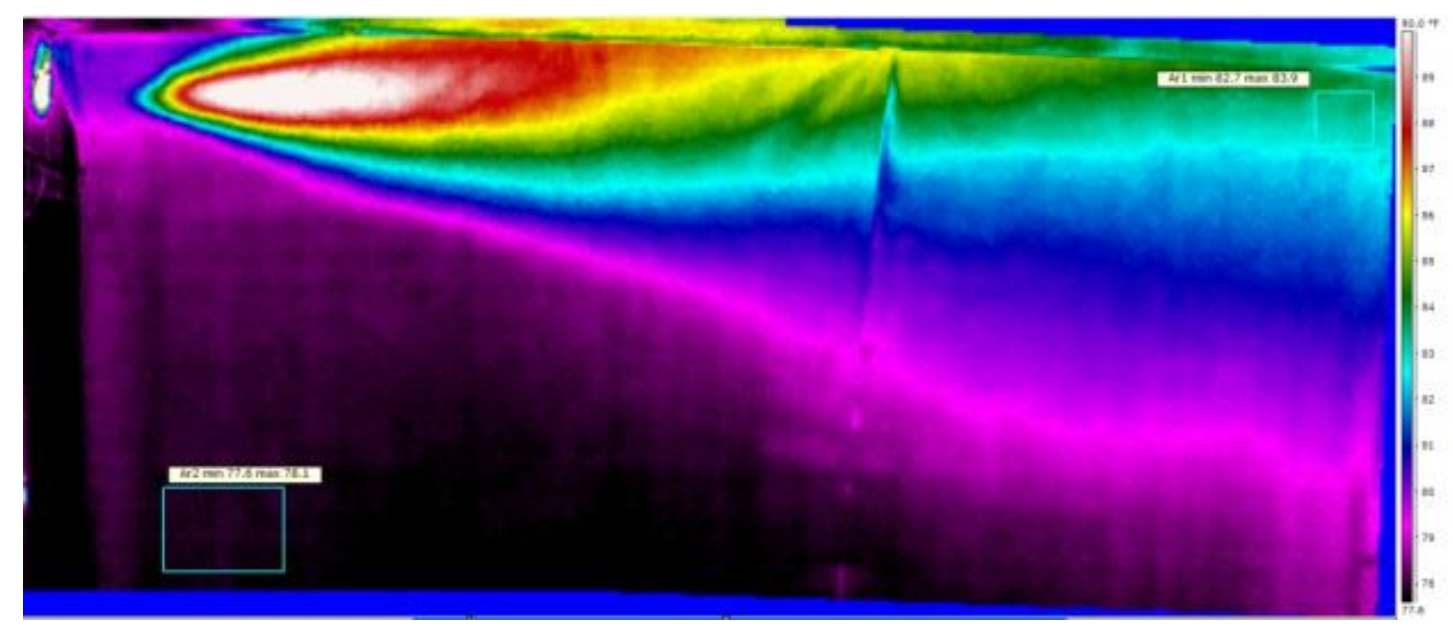

Figure 21. IR photo of the black felt screen during high-speed heating system operation (temperature scale in ${ }^{\circ} \mathrm{F}$ ) 


\section{Discussion}

The ability of all register flows to reach the exterior wall correlates positively with the measured face velocities within ACCA Manual T guidelines (Rutkowski 2009b). The researchers observed that the vertical spread increased as the flow rate increased. One might interpret this to clearly indicate the mixing ability of each flow rate; however, the difference in vertical spread also could be due, in part, to the decreased initial energy of the low flow rates making a less significant temperature gradient on the black felt. If the mixing capabilities are similar, the lower volume flow rates provided less stratification during system runtime. Based on this observation, if lower airflow rates are combined with longer system runtime, superior occupant comfort could be achieved because of lower stratification levels and lower peak room air velocities. 


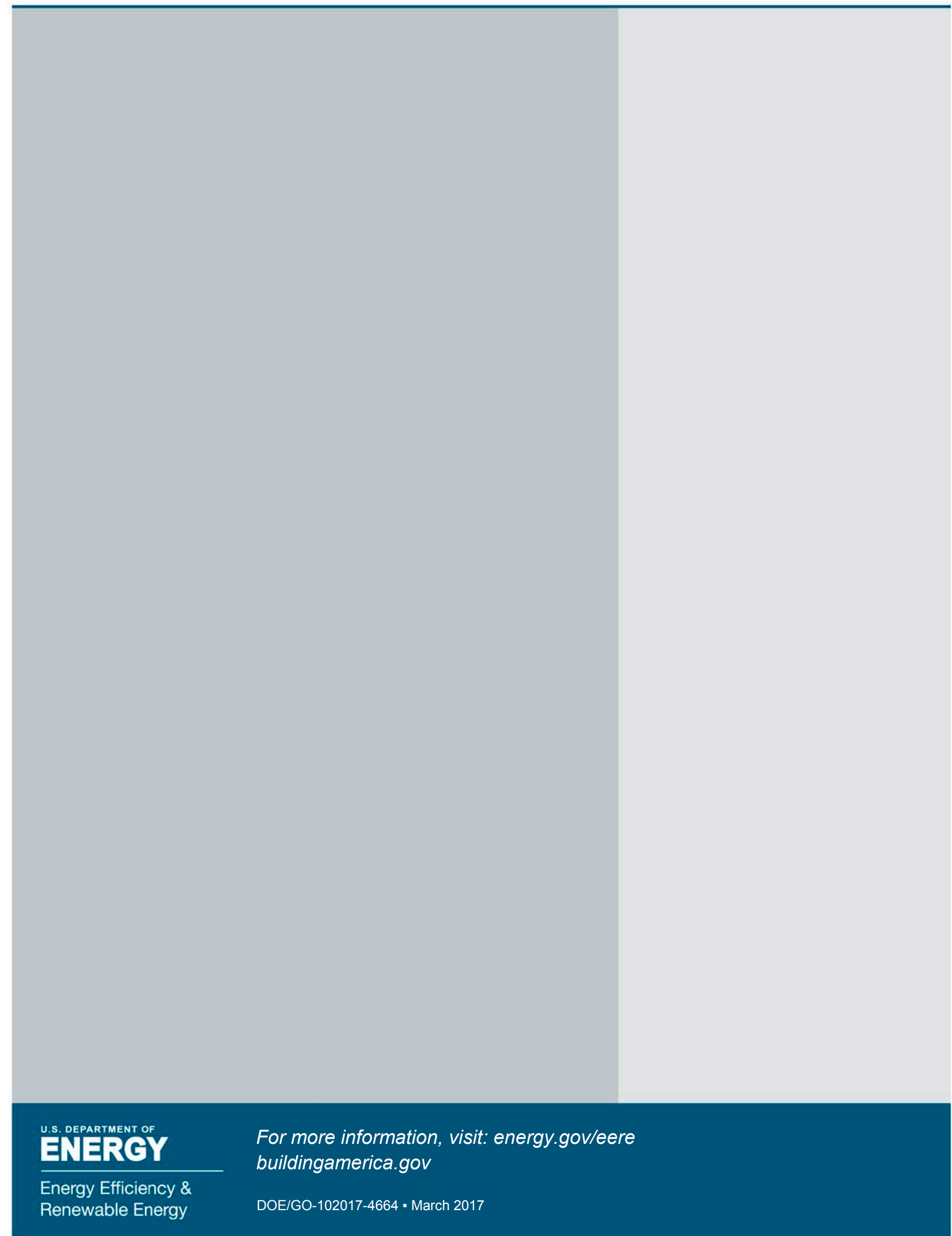

